\title{
CONSECUENCIAS DE LA TALA MADERERA COLONIAL EN LOS BOSQUES DE ALERCE DE CHILOÉ, SUR DE CHILE (SIGLOS XVI-XIX)*
}

FERNANDO TORREJÓN G.", MARCO CISTERNAS V."*, INGRID ALVIAL C."***, LAURA TORRES R."****

\begin{abstract}
RESUMEN
Durante el proceso de colonización española la madera de alerce se transformó en el principal recurso económico de Chiloé, generándose una importante actividad mercantil sustentada en la tala de dicha especie arbórea. Mediante un análisis histórico documental, que abarca desde el siglo XVI al XIX, se examinó la evolución de la tala y del comercio maderero local, evaluándose sus efectos ambientales sobre la cobertura boscosa original del territorio. Los resultados obtenidos permiten constatar que la tala colonial del alerce habría generado sólo una moderada alteración de los alerzales más accesibles, en comparación a lo ocurrido en los inicios de la República tras la notoria intensificación de la explotación maderera. En consecuencia se descarta la tradicional idea de la desaparición o extinción de alerzales en Chiloé durante el dominio colonial.
\end{abstract} ambiental.

PALABRAS CLAVE: Fitzroya cupressoides, comercio maderero, colonización española, historia

\section{COLONIAL TIMBER FELLING CONSEQUENCES OF THE ALERCE FORESTS} IN CHILOÉ, SOUTHERN CHILE (18 ${ }^{\mathrm{TH}}$ AND $19^{\mathrm{TH}}$ CENTURIES)

\begin{abstract}
During the Spanish settlement processes the wood from the Alerce tree was the main economical resource of Chiloé (Southern Chile), generating an important commercial activity in the region. The development of the Alerce timber and trading was studied based on historical-documentary analysis including data from the $16^{\text {th }}$ to $19^{\text {th }}$ century. Special attention on the environmental effect was assessed based on the original Alerce forest conditions. Findings allow concluding that the colonial Alerce removal it would

* Investigación desarrollada y financiada en el marco del Proyecto FONDECYT 1060227.

* Centro de Ciencias Ambientales EULA-Chile, Universidad de Concepción, Casilla 160-C, Concepción, Chile; ftorrejo@udec.cl.

Escuela de Ciencias del Mar, Pontificia Universidad Católica de Valparaíso, Casilla 1020, Valparaíso, Chile; marco.cisternas@ ucv.cl.

**** Centro de Estudios Avanzados en Zonas Áridas (CEAZA), Raúl Bitrán s/n, Colina El Pino La Serena, Chile; ingrid.alvial@ ceaza.cl.

Unidad Académica de Los Ángeles, Universidad de Concepción, Casilla 341. Los Ángeles, Chile; latorres@udec.cl.
\end{abstract}


have caused only a minor disturbance to the original forest, and it would have taken place within the most accessible Alerzales (Alerce patches) only, contrary to the situation observed at the beginning of the republic period when an enormous Alerce exploitation was experimented. Therefore, it has been proved that the disappearance and extinction of Alerzales in Chiloé, during the colonial domain, did not occur.

KEYWORDS: Fitzroya cupressoides, forest trade, Spanish settlement, environmental history.

\section{INTRODUCCIÓN}

El Alerce (Fitzroya cupressoides) es una especie arbórea clasificada internacionalmente como "amenazada", integra la lista CITES y, en 1976, de acuerdo a la legislación chilena, se le otorgó la categoría "Monumento Natural"1. Estudios paleo-botánicos de reconstrucción de comunidades vegetales en Chiloé continental e insular indican que los bosques de alerce han estado presentes allí durante todo el Holoceno, aunque con oscilaciones en su abundancia relativa debidas principalmente a variaciones climáticas ${ }^{2}$.

Endémica de los bosques templados de Chile, y en menor proporción de Argentina ${ }^{3}$, esta conífera puede llegar a vivir más de tres milenios; se desarrolla en diversos hábitat húmedos, desde terrenos bajos y planos pobremente drenados, en la depresión central de Chile, hasta en suelos de

1 Donoso, C., V. Sandoval y R. Grez. 1990. Silvicultura de los bosques de Fitzroya cupressoides ¿Ficción o realidad? Bosque 11: 57-67. Valdivia, Chile; pp. 57-58. Benoit, I. (ed.) 1989. Red Listo of Chilean Terrestrial Flora.. CONAF, Santiago; p. 53.

2 Villagrán C. 1991. Historia de los bosques templados del sur de Chile durante el Tardiglacial y Postglacial. Revista Chilena de Historia Natural 64: 447-460 Santiago, Chile; pp. 456-459. Moreno, P. 2004. Millenial-scale climate variability in northwest Patagonia over the last 15000 yr. Journal of Quaternary Science 19: 35-47. W. Sussex, UK; pp. 36-41. Abarzúa, A., C. Villagrán y P. Moreno. 2004. Deglacial and postglacial climate history in east-central Isla Grande de Chiloé, Southern Chile ( $\left.43^{\circ} \mathrm{S}\right)$. Quaternary Research 62: 49-59. Seattle, US; pp. 50-51.

3 Premoli, A., C. Souto, A. Lara y C. Donoso. 2004. Variación en Fitzroya cupressoides (Moll) Johnston (Alerce o Lahuán). En: Variación intraespecífica en las especies arbóreas de los bosques templados de Chile y Argentina. C. Donoso, A. Premoli, L. Gallo y R. Ipinza (eds.). Editorial Universitaria, Santiago de Chile; pp. 277-301, p. 277. Kitzberger, T., A. Perez, G. Iglesias, A. Premoli y T. Veblen. 2000. Distribución y estado de conservación del Alerce (Fitzroya cupressoides (Mol.) Johnst.) en Argentina. Bosque 21: 79-89. Valdivia, Chile; pp. 81-84. laderas y valles altos de las cordilleras de la Costa y de los Andes, sobrepasando en esta última los mil metros de altitud 4 . En la mayoría de sus hábitats el alerce crece asociado a otras especies arbóreas formando grandes bosques denominados alerzales, sin embargo, en sectores cordilleranos de la vertiente argentina se llegan a conformar bosques puros ${ }^{5}$.

Denominado originalmente lahuan, lahual o lahuén en lengua mapuche $e^{6}, F$. cupressoides era una especie completamente desconocida para los colonizadores españoles, quienes la llamaron "alerce" en el afán de asimilarla a alguna de las especies por ellos conocidas, como Larix decidua o alerce europeo ${ }^{7}$. Se estima que desde la llegada de los españoles la superficie original que cubrían los bosques de alerce ha sido fragmentada y reducida en más de la mitad: desde una cantidad superior a las 617.000 ha existentes hacia 1550 , a tan sólo unas 265.000 ha calculadas en $1997^{8}$.

4 Lara, A. y R.Villalba. 1993. A 3620-year temperature record from Fitzroya cupressoides tree rings in southern South America. Science 260: 1104-1106. Washington, DC. Donoso C. 1993. Bosques templados de Chile y Argentina. Variación, estructura y dinámica. Editorial Universitaria, Santiago; pp. 387-389. Gerding, V. y Y. Rivas. 2006. Desarrollo de plantaciones experimentales jóvenes de Fitzroya cupressoides establecidas en el arboreto de la Universidad Austral de Chile, Valdivia. Bosque 27: 155-162. Valdivia, Chile; p. 156.

5 Donoso 1993, op cit. pp. 390-394. Premoli et al. 2004, op cit. pp. 279-280.

6 Erize, E. 1960. Diccionario comentado Mapuche-Español. Cuadernos del Sur, Buenos Aires; p. 209. Rodríguez, R., O. Matthei y M. Quezada, 1983. Flora Arbórea de Chile. Editorial de la Universidad de Concepción, Concepción, Chile; p. 155.

7 Medina, A. 1984. Embarcaciones chilenas precolombinas. La Dalca de Chiloé. Revista Chilena de Antropología 4: 121-138. Santiago de Chile; p. 135

8 Wolodarsky-Franke, A. y A. Lara. 2003. La dendrocronología como herramienta en la conservación de especies arbóreas en peligro en Chile, Gestión Ambiental 9: 15-23. Valdivia, Chile; p. 19. Reyes, R. y H. Lobos 2000. Estado de conservación del tipo forestal alerce (Fitzroya cupressoides (Mol.) Johnston): amenazas y oportunidades. Bosque Nativo 27: 14-15. Valdivia, Chile; pp. 14-15. 
Si bien su extracción comercial se inició tras la consolidación de los asentamientos hispanos, a comienzos del s. XVII ${ }^{9}$, tradicionalmente se ha planteado que los alerzales chilotes fueron intensamente explotados desde el siglo $\mathrm{XVI}^{10}$, y que para inicios del s. XVIII ya se habían extinguido los principales alerzales de las partes bajas de Chiloé continental ${ }^{11}$. Sin embargo, el detallado estudio histórico que se presenta a continuación demuestra que la degradación más importante de aquellos bosques ocurrió en realidad mucho más tarde, ya en tiempos de la República.

En efecto, el análisis de la evidencia documental realizado en el presente trabajo concluye que la explotación maderera del alerce practicada en Chiloé, durante la Colonia, habría generado una moderada alteración de los alerzales y en ningún caso una masiva degradación y/o desaparición local de los mismos. Se llega a esta conclusión mediante el análisis de las características y evolución de la explotación maderera colonial, comparándola con la de inicios de la República, e infiriendo el efecto de ambas sobre los alerzales chilotes.

Para definir el área geográfica de estudio se consideraron la variable biogeográfica, referida a la distribución original de los alerzales ${ }^{12}$, y la variable humana, que vincula la evolución del poblamiento español con la tala maderera, principal actividad económica mercantil ejercida en Chiloé durante la Colonia ${ }^{13}$. Así, el área de estudio incluye el territorio de Chiloé continental e insular $\left(41^{\circ}-43.5^{\circ}\right.$ Lat.

9 Contreras, J., E. Flores, I. Herrera, L. Mazzei, A. Rivera y R. Romero, 1971. La población y la economía de Chiloé durante la colonia (1567-1826). Universidad de Concepción, Concepción, Chile; pp. 21-24.

10 Premoli et al. 2004, op cit. p. 282.

11 Cunill, P. 1971. Chile meridional criollo: su geografía humana en 1700. Cuadernos Geográficos del Sur, Número único: 21-75. Concepción, Chile; p. 62.

12 Fraver,S., M. González, F. Silla, A. Lara y M. Gardner. 1999. Composition and structure of remnant Fitzroya cupressoides forest of Southern Chile's Central Depression. Journal of the Torrey Botanical Society 126: 49-57. Lawrence, US; pp. 49-50. Premoli et al. 2004, op cit. pp. 282-283.

13 Urbina, R. 1983. La periferia meridional indiana Chiloé en el siglo XVIII. Ediciones Universitarias, Valparaíso, Chile; pp. 82-83. Torrejón, F., M. Cisternas y A. Araneda, 2004. Efectos ambientales de la colonización española desde el río Maullín al archipiélago de Chiloé, sur de Chile. Revista Chilena de Historia Natural 77: 661-677. Santiago de Chile; pp. 670-671.
S y $72.3^{\circ}-74,5^{\circ}$ Lat. O), llamado aquí simplemente "Chiloé" (Fig. 1, A-C). Durante el período colonial, entre fines del siglo XVI e inicios del siglo XIX, la jurisdicción de Chiloé abarcaba un enorme espacio geográfico, que nominalmente se extendía más allá del río Maullín, por el norte, y el cabo de Hornos por el sur ${ }^{14}$. Sin embargo, el control administrativo efectivo cubría sólo el territorio que se ha definido como área de estudio (Fig. 1, C-D). En el desarrollo del trabajo se utilizará el topónimo "Isla Grande" para referirse a la mayor de las islas del archipiélago y el topónimo "Chiloé continental" para señalar al arco continental conformado por las tierras bajas al sur del río Maullín, contorno del seno de Reloncaví y las tierras altas entre los esteros Reloncaví y Reñihue (Fig. 1, C-D).

Morfo-estructuralmente el área de estudio se caracteriza por dos grandes unidades contrastantes (Fig. 1, C): 1) Sectores altos y abruptos, con altitudes superiores a 500 metros, representados por la vertiente occidental de la cordillera de los Andes y por la cordillera de la Costa; esta última dividida en la cordillera Pelada, en el extremo norte continental, y la cordillera de Piuchén en la zona centro-occidental de la isla Grande; 2) Sectores bajos y planos, con alturas inferiores a 500 metros, compuestos principalmente por sedimentos cuaternarios que rellenaron y alisaron la depresión intermedia.

En cuanto al tratamiento de las fuentes documentales, se realizó una recopilación, selección y análisis de fuentes bibliográficas coloniales y republicanas, privilegiándose la información testimonial de primera mano, obtenida a partir de relatos de viajes, registros de exploraciones geográficas y científicas, informes administrativos, documentación epistolar y crónicas coloniales. Esta data se complementó con el estudio de cartografía histórica de los siglos XVIII y XIX. Relevante fue también el uso de trabajos científicos e historiográficos modernos, priorizándose aquéllos de ecología del paisaje, reconstrucción vegetal e historia ambiental.

14 Urbina 1983, op. cit. pp. 19-22. Guarda, G. 1990. Flandes indiano. Las fortificaciones del reino de Chile (1541-1826). Ediciones de la Universidad Católica, Santiago de Chile; pp. 128-129. Urbina, M. 2009. La frontera de arriba en Chile colonial. Ediciones Universitarias, Valparaíso, Chile; pp. 325-326. Véase también en este mismo número el artículo de Mateo Martinic (págs. 57-65). 

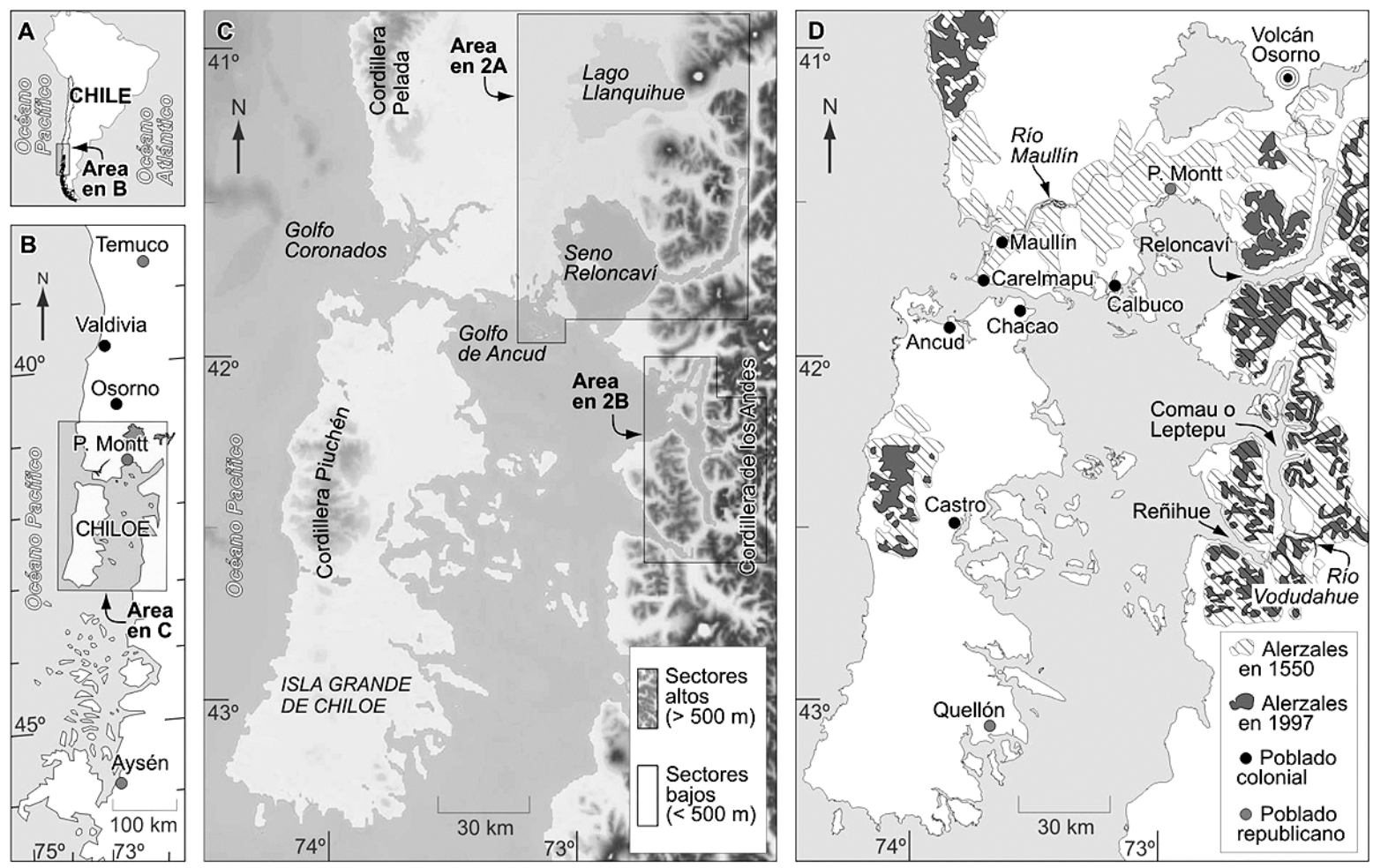

Fig. 1. A y B) Localización del área de estudio. C) Modelo Digital de Elevación que diferencia las dos principales unidades topográficas del área. D) Distribución generalizada de los alerzales ca. 1550 y en 1997.

Fuente: Elaboración propia, (D, Modificado de Wolodarsky-Franke, A. y A. Lara 2003, op cit. p. 19).

Compulsada la evidencia histórica, considerando su especificidad y calidad descriptiva, se compiló la información relativa al alerce, su entorno natural, cultural y económico entre los siglos XVI y XIX. Sobre la base de la información analizada, aplicando el método mixto de progresión y regresión histórica ${ }^{15}$, se estableció una línea de base o descripción del estado original en que se encontraban los alerzales en el territorio de Chiloé hacia fines del siglo XVI, época en que se inicia el registro histórico del uso, tala y comercio maderero de la especie. Finalmente, se comparan el registro histórico colonial (siglos XVI-XVIII) con el registro de inicios de la República (siglo XIX), evaluándose cualitativamente los efectos ambientales de la tala maderera sobre los alerzales de Chiloé.

15 Bolos, M. de. 1992. La evolución o arqueología del paisaje. En: Manual de ciencia del paisaje teoría, métodos y aplicaciones. M. de Bolós (ed.). Masson S.A., Barcelona; pp. 191-203, pp. 191-192.

\section{RESULTADOS Y DISCUSIÓN}

Distribución y uso prehispánico del alerce en Chiloé.

Cuando los primeros españoles se establecieron en Chiloé, hacia 1567, una densa vegetación cubría la mayor parte de ese territorio ${ }^{16}$, destacando allí, por la altura de los árboles, los bosques de alerce (Fig. 1, D). En Chiloé continental los alerzales se distribuían ampliamente entre la ribera meridional del lago Llanquihue, por el norte, y los fiordos Comau y Reñihue por el sur; mientras que en el sentido este-oeste, se extendían desde los Andes hasta la desembocadura del río Maullín en el Pacífico ${ }^{17}$. En la Isla Grande, los

16 Torrejón et al. 2004, op cit. p. 663. Camus, P. 2002. Bosques y tierras despejadas en el período de la conquista de Chile. En: Estudios Coloniales II. J. Retamal (ed.). RIL Editores, Santiago de Chile; pp. 159-180, pp. 174-175.

17 Donoso 1993, op. cit. p. 393. Fraver 1999, pp. 49-50. Premoli et al. 2004, op. cit. pp. 282-283. 
alerzales tenían una distribución mucho menor, restringiéndose esencialmente a la cordillera de Piuchén ${ }^{18}$.

La cerrada vegetación de Chiloé confinó el poblamiento aborigen a los bordes costeros más despejados, principalmente en la zona del estuario del río Maullín, ribera norte del canal de Chacao, costa nororiental de la Isla Grande y, en general, a las costas de las islas aledañas ${ }^{19}$. El borde costero, con terrenos abiertos o con una vegetación menos enmarañada, rico además en recursos marinos, satisfacía los requerimientos alimenticios de los indígenas. Esto permitió el desarrollo de una economía aborigen donde las faenas extractivas vinculadas al mar se complementaban exitosamente con labores agrícolas y ganaderas de pequeña escala ${ }^{20}$.

Las condiciones naturales de Chiloé promovieron el temprano uso aborigen de la madera de alerce: su fisiografía, conformada por decenas de islas, estimuló a los huilliches a construir una práctica y confiable embarcación, denominada dalca o dallca en idioma mapuche ${ }^{21}$, cuya eficacia quedó demostrada al ser adoptada y modificada posteriormente por los españoles, quienes la llamaron inapropiadamente piragua, que llegó a ser de vital en la economía colonial de Chiloé ${ }^{22}$. Absolutamente diferente a la canoa monóxila ${ }^{23}$, la dalca prehispánica se componía de tres grandes piezas de madera, que se unían entre si cosiéndolas con soguillas fabricadas de material vegetal y calafateadas con substancias del mismo origen para impermeabilizar las junturas ${ }^{24}$. Es posible

18 Reiche, K. 1934. Geografía Botánica de Chile. Imprenta Universitaria, Santiago de Chile; vol. 1, p. 382.

19 Contreras et al. 1971, op. cit. p. 13. Cárdenas, R., D. Montiel y C. Hall. 1991. Los Chonos y los Veliches de Chiloé. Ediciones Olimpho, Santiago de Chile; p. 130. Torrejón et al. 2004, op cit. pp. 663-664.

20 Oyarzún, A. 1934. Cultura aborigen de Chiloé. Revista Chilena de Historia y Geografía 83: 235-254, Santiago de Chile; p. 238. Torrejón, et al. 2004, op cit. p. 664.

21 Cárdenas et al. 1991, op. cit. p. 129.

22 Finsterbusch, C. A. 1934. Las dalcas de Chiloé y los chilotes. Revista Chilena de Historia y Geografía 82: 412-433. Santiago de Chile. p. 415. Hanisch, W. 1982. La Isla de Chiloé, Capitana de Rutas Australes. Academia Superior de Ciencias Pedagógicas de Santiago/Alfabeta Impresores, Santiago de Chile; pp. 23-24.

23 Carabias, D., N. Lira y L. Adán. 2010. Reflexiones en torno al uso de embarcaciones monóxilas en ambientes boscosos lacustres precordilleranos andinos, zona centro-sur de Chile. Magallania 38: 87-108. Punta Arenas, Chile, pp. 91-92.

24 Zapater, H. 1973. Los aborígenes chilenos a través de cronistas y viajeros. Editorial Andrés Bello, Santiago de Chile; pp. 71-72. Medina 1984, op. cit. pp. 124-127. que la dalca original fuera construida exclusivamente con alerce, madera que contaba con claras ventajas: liviana, de fibra pareja y gran resistencia a la humedad $^{25}$. Algunos autores argumentan que las dalcas prehispánicas eran construidas tanto de madera de alerce como de ciprés, sugiriendo incluso una posible coincidencia entre la localización de estas especies y el territorio donde se habría concebido y desarrollado esta embarcación ${ }^{26}$. Se sabe que en tiempos coloniales, además del alerce, la dalca fue también construida con otras maderas, como roble, coigüe o ciprés $^{27}$.

Considerando que las tempranas descripciones hispanas señalan que las dalcas indígenas llegaban a medir entre 9 y 12 metros de eslora, y unos 84 centímetros de manga ${ }^{28}$, se deduce que las piezas de madera para su construcción provenían de árboles relativamente grandes, implicando el corte selectivo de especies. De acuerdo al documentado trabajo de Cárdenas et al., la faena comenzaba con el derribo de uno o dos alerces o cipreses, los que posteriormente se dejaban secar in situ durante un año; de uno de ellos obtenían los dos tablones más apropiados para los laterales de la embarcación, y del otro la pieza única que formaría su fondo, el grosor de las tres piezas variaba entre 6 y 10 centímetros $^{29}$.

Al no contar con herramientas de hierro, tanto el volteo del árbol como la elaboración de los tablones debió ser una labor ardua para los indígenas; sin embargo, la veta del alerce, con una fibra pareja, permitía efectuar un fácil rajado longitudinal mediante cuñas de maderas duras, como la luma (Amomyrtus luma) y el tepu (Tepualia stipularis) ${ }^{30}$. También se ha sugerido la utilización de grandes ta-

25 Finsterbusch 1934, op. cit. p. 416. Medina 1984, op. cit. pp. 135-136.

26 Cárdenas et al. 1991, op. cit. pp. 129, 134.

27 Medina 1984, op. cit. p. 135. Probablemente se trataba de Nothofagus obliqua, Nothofagus dombeyi y/o Nothofagus nitida, Austrocedrus chilensis y Pilgerodendron uviferum, especies presentes en el área de estudio.

28 Medina 1984, op. cit. p. 124

29 Cárdenas et al. 1991, op cit. p. 134.

30 Armesto, J., C. Villagrán y C. Donoso. 1994. Desde la era glacial a la industrial: la historia del bosque templado chileno. Ambiente y Desarrollo 19: 66-72. Santiago de Chile; p. 68. Vidal Gormaz, F. 1871. Esploracion de la costa de Llanquihue i archipiélago de Chiloé practicada por órden del supremo Gobierno por el capitan graduado de corbeta don Francisco Vidal Gormaz. Anales de la Universidad de Chile XXXIX: 5-80. Santiago de Chile; p. 53. 
blones de madera en la construcción de las viviendas aborígenes en el Chiloé prehispánico ${ }^{31}$. La temprana evidencia documental no es concluyente al respecto, pues más bien asimila dichas viviendas a las grandes rucas mapuches de más al norte, estructuradas de varas cubiertas con tallos de gramíneas, ciperáceas o juncáceas ${ }^{32}$.

Respecto a los lugares donde los indígenas realizaban la tala, hasta la fecha la evidencia arqueológica y documental no permite determinarlos con precisión, aún cuando es posible inferirlos a base de condicionantes como la distribución original de los grandes alerzales, los patrones de asentamiento costero aborigen y la necesidad de construcción de embarcaciones. Las áreas que se ajustan a estas condicionantes son el estuario del río Maullín, la costa norte del golfo de Ancud y del seno de Reloncaví, especialmente entre Carelmapu y el actual Puerto Montt; es decir, donde se localizaban los alerzales más accesibles de los sectores bajos y cercanos a la costa de Chiloé continental.

Sobre la base de todo lo anterior es posible concluir que aunque la tala indígena del alerce debió ser constante a través del tiempo, su carácter de autoconsumo, la alta durabilidad de la madera, la corta selectiva, los rudimentos técnicos disponibles (basados principalmente en herramientas líticas) y la falta de evidencias que indiquen el uso de fuego para el despeje de la vegetación, es poco probable que la actividad maderera prehispánica haya generado algún efecto degradativo sobre los alerzales chilotes. De esta manera es posible inferir que las perturbaciones ambientales asociadas a tala aborigen prehispánica del alerce debieron ser mínimas y localmente circunscritas.

\section{Orígenes de la tala maderera colonial y su desarrollo durante el s. XVII.}

El proceso de colonización española de Chiloé se inició en 1567 con las fundaciones de San Antonio de Chacao (Chacao) y Santiago de Castro (Castro) en la Isla Grande (Fig. 1, D). Inicialmente, tras una preci-

31 Latcham, R. 1936 Prehistoria chilena. Oficina del Libro, Santiago de Chile; p. 87. Cárdenas et al. 1991, op cit. p. 130.

32 Zapater 1973, op. cit. pp. 70-71. Claude, J. 1931. La vivienda araucana. Anales de la Universidad de Chile, $3^{\text {a }}$ Serie, I: 29-48. Santiago de Chile; pp. 33-35. pitada y deficiente percepción ambiental, los nuevos pobladores intentaron desarrollar una economía local sustentada en la explotación aurífera y en el modelo agropecuario hispano-mediterráneo. Sin embargo la escasez de oro y las inadecuadas condiciones biogeográficas, en relación a la aclimatación de siembras y ganados exóticos, llevó a que este primer intento económico arrojara decepcionantes resultados ${ }^{33}$.

Este fracaso obligó a los colonos a reinterpretar y revalorar las potencialidades del entorno, asimilando, adoptando y desarrollando estrategias económico-productivas adecuadas a las duras condiciones ambientales de Chiloé ${ }^{34}$. Así comenzaría a surgir una nueva actividad económica, basada en la explotación maderera de los alerzales, principalmente de aquéllos ubicados en los sectores bajos entre Reloncaví y la desembocadura del río Mau$l_{1} n^{35}$. Esta actividad se fortaleció con la fundación de los enclaves de San Miguel de Calbuco (Calbuco), en 1602, y San Antonio de Ribera de Carelmapu (Carelmapu), en 1603 (Fig. 1, D).

A inicios del siglo XVII, la tala del bosque en Chiloé seguía siendo una actividad básicamente utilitaria, de autoconsumo, destinada a satisfacer los requerimientos locales de los españoles. La madera obtenida se usaba principalmente en la construcción de habitaciones, emplazamientos militares e indispensables embarcaciones; además el bosque proveía abundante leña para el alto consumo habitual de los colonos $^{36}$. Sin embargo, esta tradicional actividad extractiva adquiriría una creciente importancia económico-mercantil, sobre todo tras la pérdida de la plaza de Valdivia -destruida por los mapuches en 1599 y abandonada por más de cuatro décadas-, que hasta entonces era prácticamente el único asentamiento que surtía de madera de alerce al Virreinato del Perú ${ }^{37}$. Para satisfacer la incesante

33 Torrejón et al. 2004, op. cit. pp. 665-668.

34 Torrejón et al. 2004, op. cit. p. 668.

35 Urbina 1983, op. cit. pp. 24-25. Ramírez, F. 1996. Ecohistoria y destrucción en Chiloé Continental: El Valle del Vodudahue 1700-1996. En: Bases históricas del desarrollo regional de Chile. Actas de la VII Jornada Nacional de Historia Regional de Chile, 225-257, Universidad de Chile, Santiago de Chile; p. 236.

36 Contreras et al. 1971, op. cit. p. 22. Torrejón et al. 2004, op. cit. p. 666.

37 Molina, R., M. Correa, C. Smith-Ramirez y A. Gainza. 2006. Alerceros huilliches de la cordillera de la costa de Osorno. Andros Impresores, Santiago de Chile; pp. 23-24. 
demanda virreinal de materias primas, en 1641 se despacha desde Chiloé el primer envío importante de tablas de alerce, embarcándose un total de 6.010 unidades ${ }^{38}$.

Dos importantes fuentes históricas permiten caracterizar el procedimiento de explotación del alerce en Chiloé en el siglo XVII. La Historica Relacion del Reyno de Chile del jesuita Alonso de Ovalle, impresa en 1646, entrega información relativa a la actividad maderera durante la primera mitad del siglo. En tanto la Historia General de el Reyno de Chile del también jesuita Diego de Rosales, finalizada en 1674, pero publicada sólo en 1877 , describe dicha faena en la segunda mitad del siglo XVII. Se debe destacar que la información entregada por Rosales es de primera mano, pues él, a diferencia de Ovalle, estuvo en Chiloé hacia 1665 en misión evangelizadora $^{39}$ convirtiéndose en testigo privilegiado de la vida cotidiana del archipiélago.

La relación de Ovalle, probablemente el primer documento que describe explícitamente al alerce, señala que uno de los principales productos de Chiloé es tablaçon, particularmente de la madera, que llaman alerce, de que hay bosques inmensos, $y$ son los arboles tan gruesos, y crecidos, que admira. Fray Gregorio de Leon [...], dize que ay arbol de estos tan gruesso, que a penas podran rodear su tronco dos sogas, que llaman sobre cargas, y cada una tiene seis braças, y que de sus ramas sacan seiscientas tablas, las cuales son de veinte pies de largo y media vara de ancho. Y lo que mas ay que ponderar en esto, es, que estas tablas no se hazen con sierra, sino con hachas, y cuñas, con que se desperdicia, y se va en astillas otro tanto de madera, es digno de credito este autor [...] por la experiencia de quarenta y dos años, que dize vivio en Chile, y viene bien con esto lo que yo oì contar a un maesse de campo, que nacio, y se crio en esta Provincia, y es, que si dos hombres a cauallo se ponen dela una y otra vanda de uno de estos arboles tendido, y atrauesado en el suelo no se alcançan aver el vno al otro, porque lo gruesso de su gran cuerpo los sobrepuja, estas tablas [...] navegan a los puertos, y ciudades de Chile, y del Perù ${ }^{40}$.

38 Contreras et al. 1971, op. cit. p. 24.

39 Medina, J. T. 1906. Diccionario Biográfico Colonial de Chile. Imprenta Elzeviriana, Santiago de Chile; p. 766.

40 Ovalle, A. de. 1646. Historica Relacion del Reyno de Chile. por Francisco Caballo, Roma; p. 61.
Rosales agrega valiosos detalles sobre la comercialización de madera de alerce en la segunda mitad del s. XVII: El alerze es arbol de grande cuerpo y fama, por ser especie de cedro y cortarse de él mucha tablazón, en que tienen gruessa grangeria los mercaderes del Perú, que cargan cada año en Chiloé mas de quince mil tablas: cómpranlas en Chiloé a cuatro reales y en Lima las venden a veinte y cuatro cada una: es madera muy dócil $y$ incorruptible y dura mas debaxo del agua ${ }^{41}$. El autor también describe las características de la especie y la faena maderera: Es grande la corpulencia y la altura del Alerze, descollándose sobre todo el bosque, subiendo desde el tronco liso hasta lo alto, que se divide en ramas vestidas de menudas y perpetuamente verdes ojas. Engruessa tanto que quince hombres apenas pueden abrazar un arbol destos que engruessa bien, y a un mismo tiempo suelen trabajar doze hombres en cortarle con sus achas, sin estorvarse los unos a los otros. De un solo alerze a acontecido sacar con acha y cuñas y sin sierra, solo al corte, seiscientas tablas, que si las cortaran con sierras sacaran sin duda mas de mil. Cada tabla tiene por lo menos media vara de ancho y cinco de largo [...]. Herido el Alerze, derrama un licor pingüe y oloroso que bañado del aire se congela en goma muy aromatica y medicinal contra inchazones y dolores procedidos de frio. Es en fin el alerze el principe de los arboles por su incorruptibilidad y grandeza ${ }^{42}$.

La información entregada por los jesuitas es relevante para entender la relación entre la tala maderera y el estado de los alerzales durante el siglo XVII en Chiloé. Compulsándose ambas fuentes se deduce que los españoles obtenían las tablas de alerce de la misma forma en que tradicionalmente lo hacían los indígenas: esto es derribando un gran árbol para luego, mediante cuñas, rajar el tronco longitudinalmente en repetidas ocasiones. Sin embargo, el uso de hachas de hierro, introducidas por los colonizadores, facilitaba enormemente el corte de los árboles y el labrado final de las tablas. Otro antecedente de importancia se refiere al evidente aumento del volumen de madera exportada desde Chiloé durante la segunda mitad del s. XVII respecto

41 Rosales, D. de. 1877. Historia general del Reyno de Chile. Flandes Indiano. Imprenta del Mercurio, Valparaíso, Chile; vol. 1, p. 221

42 Rosales 1877, op. cit. vol. 1, p. 222. 
a la precedente. Incremento que probablemente respondió a la mayor demanda desde Chile central y, fundamentalmente, del Perú. Hacia 1674, Rosales estima que las exportaciones anuales al Perú son de 15.000 tablas, lo que casi triplica la exportación de 1641, cuando se embarcaron 6.010 tablas (Tabla 1).

Ambas fuentes históricas también dejan entrever el uso de la tala selectiva como método de explotación. Las dimensiones de las tablas obtenidas durante la segunda mitad de s. XVII, de por lo menos media vara de ancho y cinco de largo -aproximadamente 42 centímetros de ancho por 4.2 metros de largo- sugieren que se seguía privilegiando el corte de grandes alerces, cuya existencia debió haber sido relativamente común en aquella época; de hecho, los diámetros reportados superaban por mucho a los diámetros de los alerces que hoy se encuentran en Chiloé. A base de los datos específicos entregados por Ovalle (1647) y Rosales (1877), hemos calculado que los mayores ejemplares que se talaban durante el s. XVII habrían alcanzado diámetros del tronco a la altura del pecho (DAP) que oscilaban entre los seis y siete metros, mientras que en la literatura especializada sólo se reconocen diámetros máximos para el alerce que varían entre cuatro y cinco metros ${ }^{43}$.

Del análisis anterior se desprende que la actividad maderera, con fines mercantiles, en Chiloé, comienza efectivamente durante las primeras décadas del s. XVII, después del fracaso del modelo económico adoptado originalmente, consolidándose hacia fines del mismo siglo. Aún así, considerando que durante todo el siglo se aplicó la tala selectiva, es probable que esta actividad no produjera un daño significativo sobre los prístinos y extensos alerzales de Chiloé, debido a que la cantidad de árboles talados habría sido relativamente baja.

Utilizando la información histórica compilada podemos realizar una cuantificación, aunque imperfecta, de los árboles requeridos para satisfacer las exportaciones del siglo XVII. En efecto, si de un árbol grande podían extraerse 600 tablas, y durante la primera mitad del siglo se exportaban alrededor de 6.000 piezas anuales, se requirió cortar 10 árboles para satisfacer la demanda de un año, y 500 para cubrir la de toda la primera mitad del siglo XVII. Aplicando la misma restringida deducción, las 15.000

43 Donoso 1993, op. cit. p. 387. Gerding y Rivas 2006, op. cit. p. 156 tablas exportadas anualmente durante la segunda mitad de ese siglo podrían haber sido elaboradas con la tala de 25 ejemplares al año, es decir, un total de 1.250 alerces. De este modo, la exportación de todo el s. XVII pudo haber sido satisfecha con sólo 1.750 grandes alerces. Sin perjuicio de lo anterior, es probable que tanto Ovalle como Rosales describieran un caso extremo de productividad de tablas por árbol, por lo que podríamos proponer, conservadoramente, que se obtenía sólo la mitad de tablas por espécimen (300). Así, habría bastado con talar 3.500 árboles para cubrir la exportación de madera de alerce durante todo el siglo XVII. Este restringido cálculo lógicamente no considera el consumo interno de madera de alerce ni tampoco la tala de otras especies ${ }^{44}$.

\section{Los astilleros de alerce}

La explotación maderera colonial del alerce en Chiloé continental se realizó en campamentos temporales denominados astilleros ${ }^{45}$. En esos lugares los colonos, junto a una mayoritaria mano de obra indígena, efectuaban el corte de los árboles y elaboraban las tablas, acopiándolas transitoriamente in

44 Considerando que en el s. XVIII la exportación anual de tablas de alerce superó con creces a la de otras maderas locales se infiere que el predominio comercial del alerce venia dándose desde el siglo anterior. Olguín, C. 1971. Instituciones políticas y administrativas de Chiloé en el siglo XVIII. Editorial Jurídica, Santiago de Chile; pp. 49-50. Torrejón et al. 2004, op. cit. p. 670

45 Una de las acepciones del término astillero, derivado del vocablo astilla, alude directamente al lugar en el monte en que se hace el corte de leña, faena que por su naturaleza genera abundante cantidad de astillas. Este significado habría sido acuñado en América colonial, haciéndose extensivo a faenas madereras similares. Pages, A. de. Sin fecha. Gran diccionario de la Lengua Castellana (de autoridades) con ejemplos de buenos escritores antiguos y modernos. Imprenta de Ángel Ortega, Barcelona; vol. 1, p. 660. R.A.E. 1992. Diccionario de la lengua española. Espasa-Calpe, Madrid; vol. 1, p. 152. Corominas, 1976, vol. 1: 308. En Chile, específicamente en Chiloé, el uso de la palabra astillero para designar al lugar donde se cortaba la madera, era común en el s. XVIII. A este último significado se habría sumado además la antigua acepción de depósito de maderas. R.A.E. 1933. Diccionario Histórico de la Lengua Española. Imprenta de Librería y Casa Editorial Hernandon, Madrid; p. 893. R.A.E. 1992, op. cit. vol. 1, p. 152. Corominas, J. 1976. Diccionario crítico etimológico de la Lengua Castellana. Editorial Gredos, Madrid; vol. 1, p. 308. 
situ; aunque las faenas se realizaban principalmente en los meses estivales, era usual que los hacheros chilotes establecieran astilleros entre septiembre y mayo ${ }^{46}$. Se trataba de una actividad ardua, donde se permanecía un mes ó mas metido en lo espeso de la montaña cortando las tablas de alerce en que consiste su mayor ramo de comercio, sin mas alimento que papas y un poco de harina de cebada tostada revuelta con agua (llaman ulpo) que usan tambien los mas distinguidos ${ }^{47}$.

Hacia 1770 un anónimo misionero jesuita describe la actividad de los hacheros: con su piragua navegan aquellos golfos arriesgados, y van o a Renihue o a Lepteu, o a otra parte, donde saben que hay tales alerces [...], van con sus hachas, a veces un día de camino lejos de la playa, a veces menos según la distancia de los árboles que hallan. Escogen uno bueno y comienzan a hachearlo seis hombres a un tiempo, cada uno en su lugar, sin estorbarse el uno al otro, tanta es la corpulencia del árbol [...]. Dividen aquel tronco en tantas partes, que cada una tenga dos varas y media, que es la medida de la tabla en lo largo. Hacen unas cuñas de limas grandes, que metiendo una de ellas en la punta de aquellos troncos, a pocos golpes se raja de largo a largo. Y así rajado hacen unos tablones de dos varas y media de largo, como dije, y anchos una cuarta, pero gruesos cuanto pueden serlo. Pulido así el tablón, le meten una cuña a la punta, y a los dos golpes salta la tabla que necesitan. Y así las van sacando todas cuantas puede dar aquel palo, que acabado pasan a otro [...]. La mayor fatiga es conducir aquellas tablas, ya hechas, a la playa por aquellos bosques, riscos y barrancas. De un alerce sacan, a veces, quinientas tablas ${ }^{48}$.

En la segunda mitad del siglo XVIII la tala del alerce se había extendido ampliamente, desde la zona de Carelmapu y Maullín hasta el estero Reñihue en Chiloé continental (Fig. 1D). De acuer-

46 Ramírez 1996, op. cit. p. 236. Urbina 1983, op. cit. p. 73.

47 Breve descripción de la provincia de Chiloé, su población, carácter de sus habitantes, producciones y comercio. Biblioteca Nacional, Biblioteca Americana José Toribio Medina, Fondo Manuscritos, Tomo 257, Manuscrito 7464 (Microfilm Ms. M59), fs. 204-234; f. 208. MS. Santiago de Chile.

48 Noticia breve y moderna del Archipiélago de Chiloé, de su terreno, costumbres de los indios, misiones, escrita por un misionero de aquellas islas en el año 1769 y 70 . Archivo Romano de la Compañía de Jesús, Chile, V. 5. Roma. En: Hanisch, W. 1982, op. cit. pp. 220-263; p. 244. do a la progresión colonizadora, como ya se ha señalado, los astilleros se habrían ido estableciendo entre el río Maullín y Carelmapu, además del sector de Melipulli (actual Puerto Montt) y alrededores del estero de Comau o Leptepu. Este último territorio fue probablemente uno de los centros mas antiguos, porque era el punto mas cercano para los tableros del interior de Chiloé, mientras los de Calbuco i Huar se dirijian al estero de Reloncaví i a la zona de astilleros que rodean el de Melipulli ${ }^{49}$.

\section{Aumento de la explotación del alerce en la segunda mitad del siglo XVIII}

De la lectura de registros históricos del siglo XVIII se pueden deducir las primeras señales de alteraciones en la estructura de los alerzales más accesibles, especialmente de los ubicados en los sectores bajos y cercanos a la costa. La evidencia sugiere que durante el siglo XVIII los árboles que se estaban cortando ya no eran tan grandes como los del siglo anterior. En efecto, desaparecen las referencias a árboles tan gruesos que sólo podían ser talados por doce hombres trabajando al mismo tiempo, como se describía en las crónicas del siglo XVII. De hecho, en la ya citada descripción del misionero jesuita, que data de $1769-70$, se enfatiza que el corte de un alerce lo pueden hacer seis hombres a un tiempo, cada uno en su lugar, sin estorbarse el uno al otro. En el mismo sentido, también disminuye la cantidad de madera que se puede extraer desde cada árbol, reportándose que se podían obtener hasta quinientas tablas de un árbol derribado. A primera vista esta cantidad no dista mucho de las 600 tablas señaladas por Ovalle un siglo antes; sin embargo, en algún momento, posiblemente al inicio de la segunda mitad del s. XVIII, el tamaño de las tablas se había reducido notoriamente: de las antiguas tablas de 40 centímetros de ancho por 4 metros de largo, se había pasado a piezas que variaban entre 15 y 18 centímetros de ancho por unos 3,3 metros de largo ${ }^{50}$.

49 Fonck, F. (ed.). 1896. Viajes de fray Francisco Menéndez a la Cordillera. Imprenta Gillet, Valparaíso, Chile; vol. I, p. 20.

50 González de Agüeros, P. 1791. Descripción historial de la provincia y archipiélago de Chiloé, en el Reyno de Chile, y obispado de la Concepción. En la Imprenta de Don Benito Cano, España; p. 125. 
La reducción en el volumen de madera extraído por árbol sumado al menor tamaño de las tablas sugiere, necesariamente, que se estaban explotando alerces más pequeños, capaces de producir sólo la mitad del volumen de madera que se producía en el siglo XVII. Por otra parte, es importante destacar que el cambio de tamaño en las tablas de alerce obedeció además a criterios prácticos. Así lo confirma un documento de finales del siglo XVIII donde se indica: para la comodidad del embarque, así en las piraguas como en los buques que despues las transportan á Lima, se han determinado del tamaño de 3 varas de largo, poco mas de un palmo de ancho y una pulgada escasa de grueso. Los habitadores de Chiloe pasan en piraguas á tierra firme, y de allí por los esteros internan cuanto pueden; viéndose últimamente precisados á traer á hombros estas tablas desde la falda de la cordillera hasta el embarcadero ${ }^{51}$.

A mediados del siglo XVIII la producción de tablas de alerce habría sufrido una disminución transitoria atribuida al alejamiento de las áreas de explotación a zonas altas de difícil acceso ${ }^{52}$. Sin embargo, la producción aumentó paulatinamente en los años posteriores, debido probablemente al incremento del tráfico comercial entre Chiloé y el Virreinato del Perú. De hecho, en 1771, se reportan excedentes de tablas acopiados en el puerto de San Carlos (actual Ancud) esperando ser embarcados al Perú ${ }^{53}$. Dos años después, en 1773, el gobernador de Chiloé, Carlos de Beranger, destacaba la importancia de la producción y comercio maderero para los chilotes: La cordillera es su mina principal en el corte de tablas de alerce; este es el mayor ramo de su tráfico. El partido de Calbuco i Carelmapu, hace el mayor corte i son los que las tienen en abundancia estribando en estos dos partidos todo el comercio de esta provincia. Los de Castro van algunos a este corte; estas tablas son apreciadas $i$ tienen su salida para Lima i puertos intermedios ${ }^{54}$.

51 Descripción y noticia de las dos naciones Patagónica y Guaigüene, Isla de Chiloé. Biblioteca Nacional, Biblioteca Americana José Toribio Medina, Fondo Manuscritos, Tomo 257, Manuscrito 7454 (Microfilm Ms. M59), fs. 57-79, f. 76. MS. Santiago de Chile.

52 Urbina 1983, op. cit. pp. 72-73.

53 Urbina 1983, op. cit. p. 72.

54 Beranger, C. de. 1893. Relación Jeográfica de la Isla de Chiloé. Anales de la Universidad de Chile LXXXIV: 181243. Santiago de Chile; p. 221.
Otra variable que probablemente incidió en el aumento de la explotación del alerce a finales del siglo XVIII, fue el cambio de estatus jurídico de los indígenas. En 1782 la corona termina con la institución de la encomienda, que asignaba un determinado número de indígenas que vivían y trabajaran en la tierra de un encomendero. De este modo los antiguos "indios encomendados" pasaron a ser "tributarios del rey", fijándoseles un impuesto pecuniario que era pagado casi exclusivamente en tablas de alerce ${ }^{55}$. Así, la madera de alerce era el ramo esencial de exportacion y el único con que los indios pueden pagar el tributo al Soberano ${ }^{56}$. El incremento en la producción generada por los tributos indígenas queda en evidencia con el ingreso de 88.749 1/2 tablas a los Reales almacenes de Chiloé en 1790, para pagar tres años de deuda: Marzo 31. Son cargo en la cuenta de Tablas de Alerse en especie, Diez mil trescientos setenta y tres $p^{\text {os }}$ tres $r r^{s}$ valor de ochenta y dos mil novecientas ochenta y siete al precio de un real que entraron en Reales Almacenes como recaudadas de los Indios Tributarios de aquella Provincia por su adeudo de los años de 87, 88, y 89 sentados a f. 1 de este libro ${ }^{57}$. En Diciembre 31 se recaudaron, por el mismo concepto, otras 5762 1/2 tablas, completándose así el total registrado para el año $1790^{58}$. Enfrentados al nuevo tributo los indígenas debieron necesariamente recurrir a los astilleros para pagarlo, aumentado en consecuencia la presión que se venía ejerciendo sobre los alerzales.

Como resultado de todo lo anterior, la explotación del alerce sufrió un notorio incremento durante las últimas tres décadas del siglo XVIII (Tabla 1). Fray Pedro González de Agüeros, quien se radicó en Chiloé a fines de 1771, señala: sí me consta que es mucha la tablazon que hacen de esta madera: pues un año con otro salen de Chiloé para Lima

55 Olguín 1971, op. cit. p. 86.

56 Descripción y noticia de las dos naciones Patagónica y Guaigüene, Isla de Chiloé, op. cit., f. 73

57 Libro Manual de la Real Caxa de San Carlos de Chiloé. Para la cuenta del año de 1790 del Señor Gobernador Intendente D. ${ }^{n}$ Francisco Garos hasta 8 de Abril y desde el 9 del mismo al de. D. ${ }^{n}$ Juan Tomás de Vergara Ministro Gral D. ${ }^{n}$ Juan Antonio Arias Interventor. Archivo General de la Nación, Cajas Reales Chiloé, C-15, Legajo 95, Libro 374, 1790. (57 fojas), fs. 12-12v. MS. Lima, Perú.

58 Libro Manual de la Real Caxa de San Carlos de Chiloé. Para la cuenta del año de $1790 \ldots$.. op. cit. f. 51. 
Tabla 1. Número de tablas de alerce exportadas desde Chiloé, en diferentes años, entre los siglos XVII y XIX.

$\begin{array}{lcc}\text { Año } & \text { № de Tablas de Alerce } & \text { Referencias } \\ 1641 & 6.010 & \text { Contreras et al., } 1971 . \\ 1674 & 15.000 & \text { Rosales, } 1877 . \\ 1771 & 60.000 & \text { González de Agüeros, } 1791 . \\ 1782 & 100.000 & \text { Ribera, } 1897 . \\ 1786 & 160.000 & \text { Urbina, } 1983 . \\ 1789 & 200.000 & \text { Moraleda, } 1888 . \\ 1835 & 400.000 & \text { Gay, } 1849 . \\ 1870 & 985.010 & \text { Vidal Gormaz, } 1871 .\end{array}$

embarcadas de 50 á 60 mil tablas, y en algunos años presencié el embarque de mucho mayor número ${ }^{59}$. Una década después, el ingeniero militar Lázaro de Ribera, comisionado por el virrey del Perú, señalaba en su informe de 1782: Un año con otro salen de Chiloé para Lima i puertos intermedios, 100.000 tablas de alerce [...]. Cuatrocientas tablas de avellano, ral-ral, ciprés i laurel [...]. Luma $i$ cuarterones de alerce, setecientos [...]. Guiones de luma i botavaras de alerce, tres mil ${ }^{60}$. De esta última relación se deduce que la exportación anual de piezas de alerce superaba con creces a la de otras maderas locales.

Ni la creciente dificultad para explotar el alerce, ni la lejanía y aislamiento de Chiloé, impidieron que en la década de 1780 se produjera un notorio incremento del tráfico comercial con Lima. Progresivamente aumenta el número anual de naves que recalan en San Carlos, actividad que se realizaba principalmente entre diciembre y abril, cuando las condiciones meteorológicas mejoraban. En 1782 recalaban tres naves, en 1785 y 1786 se registran cinco cada año, las que aumentan a diez en 1787 y 1788 respectivamente ${ }^{61}$. Desembarcadas las mercancías importadas, usualmente sal, azúcar, aguardiente, vino, tabaco, añil, yerba del Paraguay (mate), ají, jabón, papel, paños de Quito y ropas de Castilla, los barcos retornaban al Perú cargados principalmente con madera de alerce ${ }^{62}$. Según es-

59 González de Agüeros 1791, op. cit. p. 125.

60 Ribera, L. de. 1897. Discurso que hace el alferez don Lázaro de Ribera, injeniero delineador, sobre la Provincia de Chiloé por orden del Supremo Gobierno de Lima, desde esta misma ciudad en agosto de 1782. En: Cinco relaciones Jeográficas e Hidrográficas que interesan a Chile. N. Anrique (ed.). Imprenta Elseviriana, Santiago de Chile; pp. 1-67, p. 28.

61 Urbina 1983, op. cit. p. 85.

62 Olguín 1971, op. cit. p. 55. Torrejón et al. 2004, op. cit. pp. 669-670. tadísticas del gobierno colonial, en 1782 entraron a Lima 90.000 tablas de Chiloé, mientras que en 1784 se contabilizó un total 58.600 piezas $^{63}$. Alrededor de 1786, de acuerdo al documentado registro de Urbina, la exportación de tablas de alerce alcanzó las 160.000 unidades al año ${ }^{64}$.

Sobre la base de la documentación y cifras históricas hasta aquí analizadas se puede inferir que la tala maderera en los alerzales de Chiloé colonial habría alcanzado su máxima intensidad durante la década de 1780 (Tabla 1). Esta conclusión se vería corroborada además por otros dos documentos de época. El primero de ellos, escrito posiblemente entre 1784 y 1788, expresa: son cerca de 200 mil tablas las que se extraen anualmente, y á estas debe agregarse la cantidad no indiferente que se emplean en los usos domésticos ${ }^{65}$. El segundo, fechado en San Carlos de Chiloé el 20 de agosto de 1789, indica: Esta excelente madera forma, como se ha dicho, el ramo mas activo de comercio de esta provincia, que consiste en algo más de 200.000 tablas de a 3 varas de largo, un palmo de ancho $i$ una pulgada escasa de grueso ${ }^{66}$. Considerando que ambos documentos consignan exactamente la misma cifra (200.000 tablas), es posible suponer que el segundo de ellos se haya basado en los datos entregados por el primer documento; sin embargo,

63 Documentos relativos a Chiloé. Biblioteca Nacional, Biblioteca Americana José Toribio Medina, Fondo Manuscritos, Tomo 259, Manuscrito 7493 (Microfilm Ms. M60), fs. 294-299. MS. Santiago de Chile.

64 Urbina 1983, op. cit. p. 53.

65 Descripción y noticia de las dos naciones Patagónica y Guaigüene, Isla de Chiloé, op. cit. f. 76.

66 Moraleda, J. de. 1888. Breve descripción de la provincia de Chiloé, su población, carácter de sus habitantes, producciones i comercio. En: Exploraciones Jeográficas e Hidrográficas de José de Moraleda y Montero. Imprenta Nacional, Santiago de Chile; pp. 203-228, p. 215. 
Tabla 2. Exportaciones oficiales de tablas de alerce desde Chiloé entre 1789 y 1792 , detallando el nombre de la embarcación y su destino.

\begin{tabular}{cccc}
\hline Año & № de Tablas de Alerce & Embarcación & Destino Final \\
\hline 1789 & 48.499 & Fragata Santa Rosa del Carmen & Callao / Lima \\
“ & 20.300 & Valdivia \\
1790 & 16.471 & Fragata Nuestra Señora del Carmen & Callao / Lima \\
1791 & 72.000 & Fragata Nuestra Señora del Carmen & Callao / Lima \\
1792 & 47.800 & Fragata Santa Rosalía & Callao / Lima \\
\hline Total & 205.070 & &
\end{tabular}

dicha cifra no coincide con los registros mercantiles oficiales de 1789 (Tabla 2), que reportan la salida de sólo 68.799 tablas de alerce, de las cuales 48.499 se destinaron a Lima y 20.300 a Valdivia67.

Respecto al uso doméstico de la madera de alerce en Chiloé, los registros oficiales indican que su proporción era muy inferior en comparación con el volumen exportado. Según el análisis de las cifras contenidas en los libros de la Real Caja de San Carlos, entre 1789 y 1792 se consumieron internamente sólo 2.371 tablas de alerce, utilizadas en la construcción y reparación de almacenes, cuarteles y viviendas gubernamentales de Chiloé. En cambio, durante ese mismo período, se exportaron 205.070 tablas de alerce, es decir una cantidad ochenta y seis veces superior a la consumida localmente (Tabla 2). No obstante lo señalado, ocasionalmente el uso doméstico se debió incrementar mucho más, como habría ocurrido durante la reconstrucción del fuerte San Miguel de Calbuco que, de acuerdo a un informe fechado en enero de 1797 era de madera de alerce, nuevamente construido por españoles $e$ indios del país ${ }^{68}$.

Es evidente que la intensificación de la explotación mercantil del alerce a finales del siglo XVIII, debió disminuir los alerzales más accesibles, fenómeno que ya se reconocía en la época, tal como se reporta en el informe de Lázaro de Ribera de 1782: Los crecidos cortes de tablas de alerce que se han hecho hasta aquí en el continente, han ido retirando el bosque de modo que en el dia ya dista mas de diez leguas de la isla grande de Chiloé69.

67 Libro Mayor de la Real caja de San Carlos de Chiloé. Archivo General de la Nación, Cajas Reales Chiloé, C-15, Legajo 94, Libro 373, 1789 (sin número de fojas). MS. Lima, Perú.

68 O'Higgins, T. 1942. Diario de viaje del capitán D. Tomás O'Higgins, de orden del virrey de Lima, el marqués de Osorno. 1796-1797. Revista Chilena de Historia y Geografía 101: 42-97. Santiago de Chile; p. 82.

69 Ribera 1897, op. cit. p. 22.
No obstante a que los documentos estudiados coinciden en señalar que la mayor explotación colonial de los alerzales chilotes ocurrió claramente hacia fines del siglo XVIII, algunos autores han planteado que esta actividad económica, en realidad, se habría iniciado más temprano; concordando asimismo en que dicha explotación generó importantes alteraciones en la distribución espacial del alerce. De acuerdo a Premoli et al., los alerzales comenzaron a ser intensamente explotados ya en el s. XVI ${ }^{70}$. Según Ramírez, desde mediados del s. XVII, esta explotación fue paulatinamente agotando las manchas madereras [...] terminando con el alerce costero, dando paso a la extracción de los ejemplares de montaña ${ }^{71}$. Cunill concluye, de manera taxativa, que hacia 1700 ya estaban extinguidos los principales alerzales de las partes bajas [de Chiloé continental], extendiéndose su explotación a las cumbres de los cerros y lugares accidentados ${ }^{72}$.

Una posible forma de solucionar la contradicción planteada, es determinar desde dónde los hacheros chilotes obtenían la madera de alerce hacia fines del siglo XVIII. Si consideramos las bajas y lentas tasas de regeneración y crecimiento de la especie $e^{73}$, es poco probable que, de haber desaparecido de los sectores planos cercanos a la costa a inicios del siglo XVIII, hubiese sido viable allí su explotación a finales de aquel mismo siglo.

Por otra parte, el detallado informe de José de Moraleda señala claramente las áreas de extracción en 1789: Los astilleros (así llaman a los sitios donde hacen los cortes) mas frecuentados i de donde sale el mayor número de tablas están en la jurisdicion de Calbuco i son Contao, el estero de Coitue, el

70 Premoli et al. 2004, op. cit. p. 282.

71 Ramírez 1996, op. cit. p. 236.

72 Cunill 1971, op. cit. p. 62.

73 Gerding y Rivas 2006, op. cit. p. 156. Donoso et al. 1990, op. cit. pp. 60-61. 

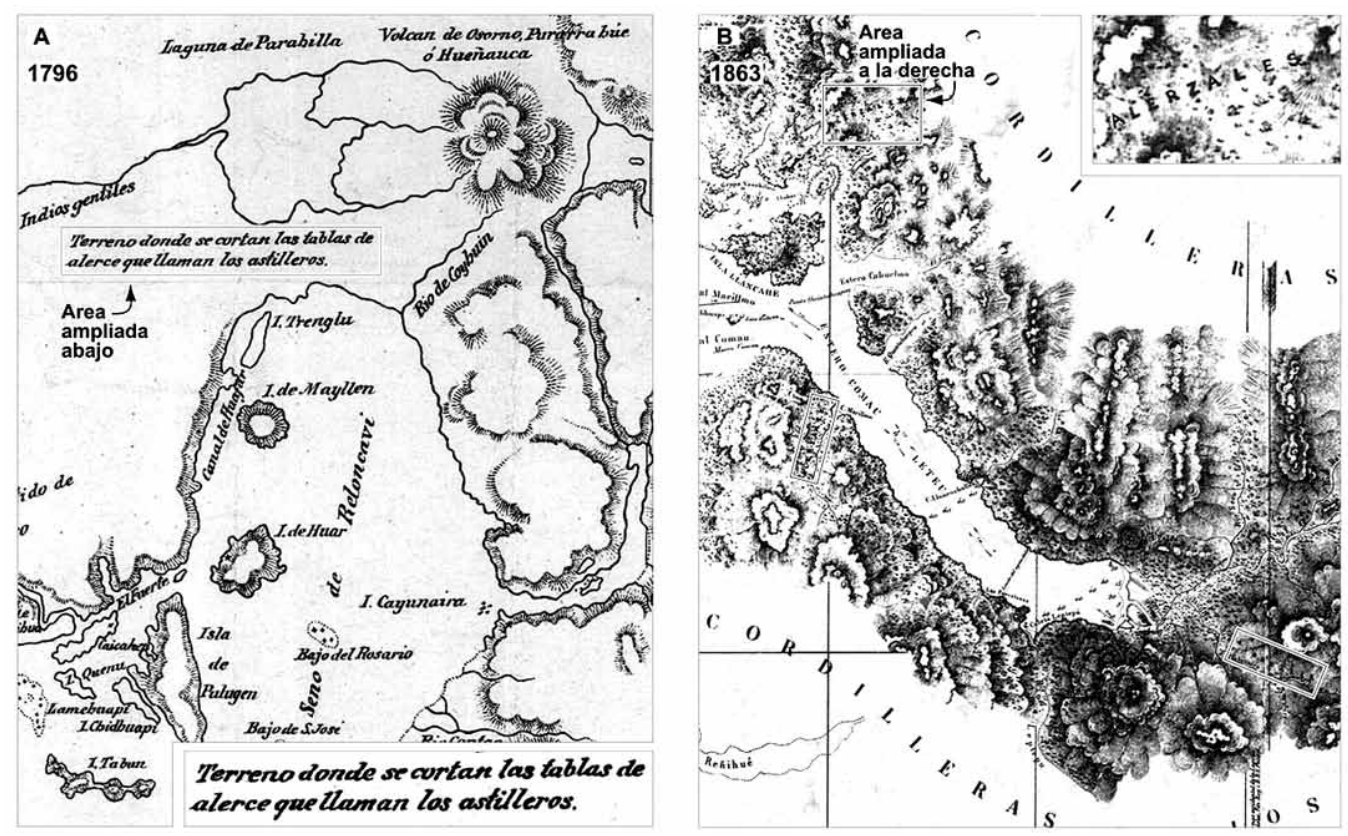

Fig. 2. Mapas históricos. A) Sección y detalle del mapa de José de Moraleda, levantado entre 1792 y 1796 , mostrando la principal zona de tala de alerce a finales del s. XVIII. B) Sección y detalle del Plano Estero Comau y Rio Bodudahue, levantado por Vidal Gormaz en 1863, donde abunda el topónimo alerzales.

rio Coihuin, Cayenel i la manga distante de 8 a 9 leguas del fuerte de Calbuco i de 22 a 24 de este puerto de San Carlos, esto es por lo que hace a navegacion, a que se deben agregar 6 o 8 mas que hai desde la orilla del mar hasta el lugar donde hacen las tablas [...]. En el partido de Carelmapu hai otros astilleros a los cuales se dirijen por el rio Palihué, que tambien llaman de la Cordillera, cuya boca está una legua escasa al oeste del fuerte de Maullín i de siete a ocho al norte de San Carlos $^{74}$. Congruentemente, un mapa levantado por el mismo Moraleda, entre 1792 y 1796, señala explícitamente que los sectores planos y bajos, comprendidos entre la ribera sur del lago Llanquihue y la costa del seno de Reloncaví, corresponde al Terreno donde se cortan las tablas de alerce que llaman los astilleros ${ }^{75}$, tal

74 Moraleda 1888 , op. cit. p. 216.

75 Carta Esférica que contiene la Costa occidental patagónica comprendida entre los 41 y 46 grados de latitud meridional con inclusión del pequeño archipiélago de Chiloé y parte del grande de Los Chonos. Reconocida y levantada de real orden y Comisión del Excelentísimo Señor Bahylio Frey D. ${ }^{n}$ Francisco Gil y Lemos, Virrey del Perú, por el Alferez de Fragata, Primer Piloto de la real Armada, D. ${ }^{\mathrm{n}}$ José de Moraleda, en los años de 1792 á 1796. Biblioteca Nacional, Memoria Chilena, MC 0018330. Santiago de Chile como se anota en dicho mapa (Fig. 2, A). Incluso medio siglo después, en 1846, otro mapa, elaborado por Bernardo Philippi, muestra que la misma zona está cubierta por Bosques virgines [sic], despoblados, con manchas de Alerze explotados por los Chilotes, incluyendo además el topónimo Astillero de Reloncavi ${ }^{76}$.

De este modo es posible confirmar que, a finales del s. XVIII, el corte del alerce se continuaba realizando en las antiguas áreas madereras, que se distribuían en los terrenos bajos y planos en los alrededores de Maullín, Carelmapu y área adyacente al seno de Reloncaví; como también en sectores cordilleranos, próximos a los esteros (fiordos) $\mathrm{Re}$ loncaví, Comau y Reñihue (Fig. 1, D y Fig. 2, A). Por lo tanto debemos descartar la tesis del temprano agotamiento o extinción del alerce en estas áreas,

76 Mapa de la provincia de Valdivia según los datos de la estadística que se han podido recoger hasta ahora, construido por Bernardo E. Philippi 1846. Biblioteca Nacional, Sala Medina, Mapoteca, B18 (1). Santiago de Chile. Es importante mencionar que en este mapa, la sección de cordillera de la costa que se extiende hacia el sur de Valdivia, llamada actualmente Cordillera Pelada, se la denominaba entonces con el sugerente nombre de Cordillera del Alerce. 
entre fines del s. XVII e inicios del s. XVIII. Aún cuando la producción máxima de unas 200.000 tablas anuales, que implicaba la tala de unos 400 árboles (considerando que se podían obtener 500 tablas por árbol), habría generado alteraciones notorias en la estructura de algunos alerzales, estas alteraciones no fueron suficientes para hacerlos desaparecer de los terrenos bajos durante la Colonia. Es muy probable que esto se haya debido a la tala selectiva, método de explotación maderera utilizado durante todo el periodo colonial.

El abandono de la tala selectiva colonial y la explotación intensiva republicana.

Los registros históricos ponen en evidencia que durante la Colonia se practicó casi exclusivamente la tala selectiva del alerce, es decir, se cortaban sólo los especímenes más grandes y por ende más rentables. Este procedimiento habría contribuido inadvertidamente a la supervivencia de muchos alerzales, a pesar de la persistente explotación a la que estuvieron sometidos en las últimas décadas del siglo XVIII. De hecho, esta práctica aún se mantenía vigente hacia 1796: Imagínese pues la magestuosa vista de un bosque inmenso todo lleno de esta clase de árboles: son de la especie de los cedros: crecen muy rectos con estraordinaria sanidad $y$ permanencia y son tan robustos y corpulentos que no es extraordinario sacar de uno de ellos 500 , ó 600 tablas [...], habiendo llegado alguna vez á 800: pero á lo menos es comun no derribar los árboles que no alcancen á suministrar 200 tablas $^{77}$.

Aunque la tala selectiva colonial contribuyó tal vez a la conservación, no evitó que los alerzales más cercanos a la costa quedaran muy disminuidos y raleados, perdurando sólo ejemplares pequeños. Robert Fitzroy, quien visitó Chiloé poco después de la independencia, en 1829, señala: Los bosques de alerce son para el calbucano como minas [...]. Las partes aprovechables de los bosques están ahora, naturalmente, más alejadas del mar que antes, debido a la constante tala. Para obtener un cargamento de veinte tablones se necesita así un trabajo doble del exigido hace treinta años. El alerce más grande hallado por un calbucano, de cuarenta años

77 Descripción y noticia de las dos naciones Patagónica y Guaigüene, Isla de Chiloé, op. cit. f. 76. a esta parte, medía 30 pies de circunferencia a cinco pies del suelo, y más de 65 pies hasta llegar a las primeras ramas [...]. Los dos árboles más grandes vistos por Mr. Douglas, en la excursión realizada por mi orden, median uno 24 y el otro 22 pies de circunferencia, a cinco pies del suelo; pero eran árboles muertos, de alma hueca. No vio uno solo de más de 10 pies de circunferencia que estuviera completamente sano. Dicen, sin embargo, que en la cordillera, fuera del alcance de los leñadores de Calbuco, hay árboles enormes, de 30 a 40 a pies de circunferencia, y de 80 a 90 de altura hasta las primeras ramas, sobre las cuales se dice que las copas de estos gigantes, se elevan otros 40 a 50 pies $^{78}$. De este modo, el explorador inglés corrobora que los alerzales ubicados en los sectores bajos, cercanos a la costa, aunque aun existían, estaban notoriamente intervenidos, con ejemplares cuyos diámetros oscilaban 1 y 2.4 metros. Sólo los sectores más altos, en las montañas andinas, se habrían conservado relativamente prístinos.

Contratado por el Gobierno chileno para estudiar la historia natural de la naciente República, el renombrado naturalista francés Claudio Gay visita Chiloé en 1835. En su tratado de botánica señala: El alerze se cria con mucha abundancia en las provincias del sur desde los cerros del puerto de Valdivia hasta Chiloé. Es árbol muy recto de grande altura, y de un grueso tal que se necesita cinco, seis y hasta siete hombres para poderlo abrazar. Se trabaja desde una época muy remota $y$ en gran cantidad ${ }^{79}$. Su descripción nos entrega además información respecto a la gran cantidad de usos que entonces tenía la madera de alerce, lo que podría explicar el aumento del interés por esta madera: sirve para hacer vigas, viguetas, cuartones, y principalmente tablas para cubiertas de casas, de buques o para hacer puertas, ventanas, barriles, muebles y muchos otros objetos ${ }^{80}$.

Coincidiendo con lo informado por Fitzroy, respecto a la duplicación del esfuerzo de explotación en comparación con el periodo colonial, Gay señala:

78 Fitzroy, R. 1933. Narración de los viajes de levantamiento de los buques de S. M. "Adventure" y "Beagle" en los años 1826 a 1836. Biblioteca del Oficial de Marina, Buenos Aires; vol. 2, p. 476.

79 Gay, C. 1849. Historia Física y Política de Chile. Botánica. Imprenta de E. Thunot y Ca , Paris; vol. 5, p. 408.

80 Ibid. 
Esta industria es muy trabajosa, porque los lugares de los Alerzales, llamados en el país Astilleros, son algo distantes y los trabajadores tienen que cargar las tablas o vigas para llevarlas a la costa pasando por caminos siempre muy malos y a veces peligrosos ${ }^{81}$. El naturalista entrega además valiosas estadísticas relativas a la explotación del alerce: Según personas competentes se puede calcular a 6000 personas hombres y chicos, empleados en verano a este trabajo, y a 3 o 400.000 el número de tablas esportadas de la provincia ${ }^{82}$. Estas cifras permiten deducir que durante los inicios de la República la presión sobre los alerzales se había incrementado considerablemente, pasándose de un máximo de 200.000 tablas anuales, exportadas a fines del siglo XVIII, a 400.000 expedidas algunas décadas después, aumento que se iría haciendo más evidente en los años posteriores (Tabla 1, Fig. 3).

Finalmente Gay nombra lugares específicos donde se realizaba la tala maderera, aludiendo también a la abundancia de la madera de alerce: los principales astilleros se hallan en Tenglu, Carinel, Melipulli, Cohuin, la Boca, etc. En el departamento de Calbuco las tablas de este árbol son tan comunes que sirven de moneda y están recibidas como tal en todos los almacenes y bodegones ${ }^{83}$. Llama la atención que la mayoría de dichos astilleros se encuentran muy cercanos a la costa del seno de Reloncaví, zona que se venía explotando desde la colonia y que al parecer aún producían una ingente cantidad de madera de alerce.

En general la descripción de Gay, más optimista que la efectuada por Fitzroy década y media antes, permite inferir que los alerzales de los terrenos bajos aún podían ofrecer madera de calidad, lo cual lleva a pensar que todavía existía una cantidad importante de bosques de alerce en dichos lugares, aunque no se puede precisar su estado de conservación. En efecto, en la década de 1840 la existencia de alerzales en el territorio adyacente a Reloncaví era notoria, así lo ratifica la información proporcionada por Ignacio Domeyko, otro estudioso comisionado por el Gobierno de Chile: Hace apenas siete a ocho años [1842-43] que el señor Espiñeira, intendente en aquel tiempo de Chiloé, recorrió con don Bernardo Philippi el corto trecho de 3 a 4 leguas

81 Ibid.

82 Ibid.

83 Gay 1849 , op. cit. vol. 5, pp. 408-409.

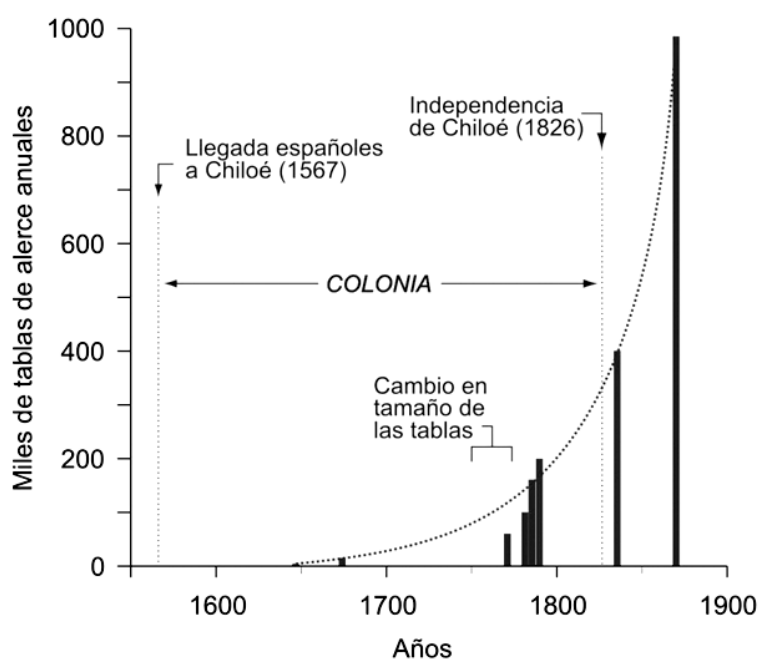

Fig. 3. Evolución de las exportaciones anuales de tablas de alerce desde Chiloé entre el siglo XVII y XIX (basada en los datos de la Tabla 1). Debido a la baja cantidad de datos disponibles, la curva punteada sólo representa un ajuste gráfico generalizado y no matemático.

que separa el golfo de Reloncavi de la laguna de Llanquigüe, trecho completamente cubierto de alerzales i de fácil tránsito ${ }^{84}$. Aparentemente, esta abundancia de alerces también se replicaba en torno al río Maullín, donde en 1859 la corta y elaboración de madera se mantenía como la principal actividad económica de aquella zona ${ }^{85}$.

Ya en plena República, el explorador chileno Vidal Gormaz describe los remanentes de alerzales que, en 1871, se extendían entorno al seno de Reloncaví, entre la ribera sur del lago Llanquihue y el mar: Los campos [...] son boscosos, ostentando cerca del camino estraordinaria tronquería de alerce, árboles que fueron derribados muchos años há i que ahora solo son como los sócalos de esas hermosas columnas que abatió la destructora hacha del maderero ${ }^{86}$. El antiguo sector de Melipulli (alrededores del actual Puerto Montt), es descrito

84 Domeyko, I. 1850. Exploración de las lagunas de Llauquigüe i de Pichilaguna - Volcanes de Osorno i de Calbuco - Cordillera de Nauelhuapi. Anales de la Universidad de Chile (sin número): 145-147. Santiago de Chile; p. 146.

85 Williams, J. 1859. Lijera reseña del rio Maullin de Chiloé, acompañada de una sucinta dirección para la navegación de la entrada de dicho rio; por el capitán de corbeta don Juan Williams. Anales de la Universidad de Chile XVI: 392-401. Santiago de Chile; pp. 397-398.

86 Vidal Gormaz, op. cit. pp. 68-69. 
indicando: solo campean a orillas del camino los corpulentos troncos de viejos alerces, explotados en los primeros tiempos del coloniaje ${ }^{87}$. El autor enfatiza además que todos estos raleados alerzales aun continuaban siendo explotados. La existencia de madera aprovechable en la zona es corroborada un año después cuando Tornero reseña el mismo trayecto entre Puerto Montt y Llanquihue: Este camino ha sido abierto en medio de un tupido bosque de árboles corpulentos [...]. A pesar del corte constante de los árboles, se encuentra todavía a orillas del camino troncos de alerce de 60 pies de circunferencia, cuyo material bastaría para techar una catedral ${ }^{88}$.

En su informe, Vidal Gormaz incluye interesantes datos sobre la producción maderera, los que demuestran claramente la brutal intensificación de la tala de alerce en Chiloé en las últimas décadas del primer siglo de vida republicana. De acuerdo a sus cifras, en 1870 se elaboró para comercio la sorprendente cantidad de 929.280 tablas y mas de 55.730 "tablones" de alerce ${ }^{89}$, volumen que quintuplicaba la máxima producción colonial de tablas, alcanzada un siglo antes, en la década de 1780 (Tabla 1 y Fig. 3). Lograr este millón de piezas, utilizando la misma tecnología colonial -esencialmente hachas y cuñas de madera- tal como lo asevera el mismo autor ${ }^{90}$, requirió necesariamente una intensificación de la explotación, llegándose incluso a emplear agresivos métodos de tala indiscriminada o tala rasa.

El corte indiscriminado de alerces se habría producido como resultado de la alta rentabilidad de la actividad maderera, la que habría atraído a más personas a participar de ella, intensificando notoriamente la presión sobre alerzales previamente raleados. En este contexto Fonck detalla la evolución que fue experimentando el proceso de explotación de los alerzales de Chiloé continental durante el siglo XIX: Habiendo ellos [los tableros] descubierto una mancha de alerce, que no esté demasiado distante de algun puerto cómodo de embarque, el astillero, hacen entre varios un sendero [...].

87 Vidal Gormaz, op. cit. p. 70.

88 Tornero, R. 1872. Chile Ilustrado. Guía descriptivo del territorio de Chile, de las capitales de provincia, i de los puertos principales. Librerías i Agencias del Mercurio, Valparaíso, Chile; p. 376.

89 Vidal Gormaz, op. cit. p. 75.

90 Vidal Gormaz, op. cit. p. 53.
Siendo trabajadores espertos escojen solo los palos mas fáciles de voltear i de mejor calidad, es decir mas dóciles para rajar en tablas, para obtener así en poco tiempo el mayor número de ellas. En las estaciones siguientes de corte se dirijen a otros lugares de condiciones análogas. A estos siguen otros tableros menos diestros i emprendedores, que se establecen en la mancha abandonada por los primeros i que, no aspirando a un provecho mayor, procuran sacar unas cuantas tablas de los palos sobrantes de inferior calidad. Actualmente se trabajan varios alerzales donde "ya pasó el antiguo". Por último habiéndose acabado la madera útil para tablas, se van aprovechando en nuestra época los restos de los trozos para durmientes de ferrocarriles. Así sucede que estos alerzales no se hayan agotado aun despues de más de cien años de constante explotación ${ }^{91}$.

Otra variable que afectó significativamente a los alerzales a finales del s XIX fue la incipiente mecanización de la explotación maderera. En 1897 ya se había instalado al menos un aserradero a vapor en el estero Reñihue (Fig. 1D), cuyos terrenos adyacentes presentaban grandes superficies boscosas, relativamente prístinas, donde proliferaba el alerce. En tierra existe al presente una máquina á vapor para elaborar maderas, perteneciente al señor Antonis, y según noticias que obtuvimos, asierra 500 tablas diarias ${ }^{92}$. Aún cuando no se especifica el tipo de madera procesada, la información entregada por Maldonado permite comparar la eficiencia productiva del sistema mecánico (500 tablas diarias), frente a la elaboración manual donde, de acuerdo a Vidal Gormaz, un hachero chilote podía labrar entre 100 y 150 tablas durante una semana de arduo trabajo93.

Como respuesta al explosivo aumento de la demanda de madera de alerce en la naciente República de Chile, la producción de tablas creció exponencialmente después de la independencia (Fig. 3). Sin lugar a dudas esto generó un enorme impacto sobre los alerzales, principalmente de los sectores bajos, pero también en aquéllos menos accesibles. Esta comparativamente alta producción maderera se cimentó en el aumento de las personas dedicadas

91 Fonck 1896, op. cit. p. 21.

92 Maldonado, R. 1897. Estudios geográficos é hidrográficos sobre Chiloé. Establecimiento Poligráfico Roma, Santiago de Chile; p. 140.

93 Vidal Gormaz 1871, op. cit. p. 56. 
a la actividad, en el método de tala indiscriminada y más tarde en el desarrollo de la mecanización productiva; variables que incrementarían el proceso de degradación y, finalmente, desaparición de muchos alerzales de Chiloé continental.

Supervivencia de los alerzales más inaccesibles.

Los alerzales localizados en la vertiente occidental de los Andes, en altura y alejados de la costa, aún se encontraban relativamente prístinos a fines del s. XIX. Los mapas de Vidal Gormaz, Estero Comau y Rio Bodudahue ${ }^{94}$, levantado en 1863 (Fig. 2, B) y Estero Reloncavi ${ }^{95}$ en 1871 , muestran los sectores altos, que rodean a ambos fiordos, cubiertos por bosques, donde abundan las referencias a los alerces. En efecto, el explorador usa la leyenda Alerzales cuatro veces en el primer mapa y Alerzal otras cinco veces en el segundo; usando también los topónimos Gran Alerzal y Alerzal del Puelche.

Así también un interesante testimonio de 1890-91 da cuenta de este común escenario: penetrando hasta la laguna [Abascal] que dista cuatro kilómetros del fondo del estero Cahuelmó [fiordo pequeño que desemboca en el de Comau]. La distancia se recorre en uno de los "caminos de alerce" tan usuales en las cordilleras del litoral de Llanquihue, i el riachuelo que baja al mar se utiliza para balsear las tablillas de alerce [...] la laguna tiene escasas playas i está rodeada de cerros que caen a plomo, habiendo tan gran cantidad de alerces en sus alrededores, que se podria explotarlos con 500 hombres aun durante diez años sin necesidad de ir a las alturas de difícil accesos ${ }^{96}$. Fonck también diferencia el estado de conservación de los alerzales del sector costero respecto a los cordilleranos más inaccesibles: El alerce está ya mui escaso en la

94 Plano del Estero Comau y Rio Bodudahue por el Teniente $2^{\circ}$ de la Armada D. Francisco Vidal Gormaz. Enero de 1863. Biblioteca Nacional, Sala Medina, Mapoteca, B18. Santiago de Chile.

95 Plano del Estero de Reloncaví (Provincia de Llanquihue) levantado de orden del Supremo Gobierno por Francisco Vidal Gormaz C. G. de C. i los oficiales de la Goleta Covadonga en 1871. (Escala 1: 80000). Biblioteca Nacional, Sala Medina, Mapoteca, B18.

96 Steffen, H. 1913. Documentos relativos a una espedicion colonial a las cordilleras australes de Chile. Imprenta, Litografía i Encuadernación Barcelona, Santiago de Chile; pp. 38-39. falda marítima de la Cordillera, que es por ahora la única accesible. Más adentro, donde Menéndez i los esploradores modernos le encontraron tambien, existe abundante $i$ en estado virginal ${ }^{97}$. De este modo la evidencia histórica demuestra que, hacia fines del s. XIX, era posible encontrar alerzales poco intervenidos o incluso prístinos en el territorio cordillerano de Chiloé, donde aún crecían grandes alerces, similares a los descritos durante la Colonia. Estos ejemplares alcanzaban diámetros entre tres y cuatro metros, e incluso de cinco i más metros en Reñihue ${ }^{98}$.

Otro sector que preservaría en buen estado sus alerzales se ubica, paradójicamente, en la Isla Grande de Chiloé, donde se encontraba la mayor población de hacheros y los principales centros de acopio; se trata de los alerzales relictos de la cordillera de Piuchén (Fig. 1, C). También en este caso la abrupta geografía habría impedido su explotación durante la Colonia y el primer siglo de historia republicana. El buen estado de los alerzales de Piuchén hacia 1895 pareciera quedar en evidencia con la descripción que hace Maldonado: Desde el campamento vimos por primera vez los alerzales (fistzroya patagónica) y cipresales de las montañas de Piuchué [sic], que corre de N. á S. por el centro de la isla Grande y se hacían notar por su forma cónica y sus troncos cenicientos muy característicos ${ }^{99}$.

Aún cuando Urbina supone que, durante el siglo XVIII, el corte de alerce también se realizó en alguna proporción en la Isla Grande ${ }^{100}$, hasta ahora nos ha sido imposible encontrar alguna referencia colonial que compruebe la explotación mercantil del alerce en la Cordillera de Piuchén. Cómo se explica que los hacheros chilotes prefirieran explotar los alerzales, aparentemente más lejanos, fuera de la Isla Grande, si desde los siglos coloniales la mayor parte de la población se distribuía en la costa nororiental de dicha isla, donde se encontraban los puertos de Chacao y San Carlos (Ancud), principales sitios de acopio y exportación de madera de alerce ${ }^{101}$. Es probable que para los hacheros haya sido mucho más fácil navegar el mar interior de Chiloé, arribar

\footnotetext{
97 Fonck, 1896, op. cit. p. 21.

98 Weber, A. 1903. Chiloé su estado actual, su colonización, su porvenir. Imprenta Mejía, Santiago de Chile; p. 53.

99 Maldonado 1897 p. 41.

100 Urbina 1983, op. cit. p. 72.

101 Ibid.
} 
a las costas cordilleranas andinas, abrir un relativamente corto camino de penetración, realizar la tala y finalmente transportar por mar las tablas hacia los puertos de acopio, que internarse en la cerrada vegetación del interior de la isla, cruzar sus tierras pantanosas, enfrentar la escabrosa topografía de Piuchén, talar, y repetir todo el camino de vuelta con la carga para alcanzar los centros de acopio.

Esta exclusión se habría mantenido al menos hasta fines del s. XIX, cuando se generó un incipiente interés por explotar la madera del interior de la isla, dada su calidad superior y apropiada para la elaboración ${ }^{102}$. Sin embargo, aquellas intenciones no habrían prosperado del todo, pues ya entrado el s. XX, el botánico Karl Reiche reportaba: El interior de la Isla asciende hasta los $800 \mathrm{~m}$. más o menos y sus condiciones de vida son semejantes a las de la Cordillera Pelada situada en el Sur de la provincia de Valdivia, y, por consiguiente, hay semejanzas en su vegetación [...]. En la ladera occidental de este cordón, o sea mirando al Océano, hay alerzales y tepuales con grandes troncos [...]. A causa de las dificultades de transporte, estos alerzales de la ladera occidental no son explotados, apenas suele aprovecharse la corteza ${ }^{103}$.

\section{CONCLUSIONES}

Basados en el análisis de la evidencia histórica presentada, es posible concluir que la degradación de los alerzales chilotes ocurrió tardíamente, ya en tiempos de la República y no durante la Colonia como tradicionalmente se ha planteado. La explotación maderera del alerce practicada en Chiloé colonial, sustentada en la tala selectiva, habría generado sólo una moderada alteración de los alerzales más accesibles, localizados en los sectores bajos y cercanos a la costa, y en ningún caso su desaparición o extinción. Por el contrario, el aumento exponencial de la producción de tablas ocurrido durante el primer siglo de la República, cimentado en la tala indiscriminada, habría aniquilado los alerzales más accesibles y degradado muchos de aquellos bosques localizados en los sectores altos y más abruptos.

102 Leguas, A. 1897. Memoria del ayudante de la comisión, Sr. Aurelio Leguas A. En: Estudios geográficos é hidrográficos sobre Chiloé. R. Maldonado. Establecimiento Poligráfico "Roma", Santiago de Chile, pp. 313-363, p. 317.

103 Reiche 1934, op. cit. p. 382.
Las principales variables que determinaron el moderado impacto de la explotación del alerce durante la Colonia fueron: 1) las condicionantes del paisaje, conformado por espesos bosques, una topografía abrupta y, en general, por las dificultades de conexión territorial; 2) el método de explotación, tala selectiva, donde sólo se cortaban los ejemplares más grandes; 3) la tecnología elemental utilizada en las faenas, principalmente hacha y cuñas que permitían que un hachero produjera sólo hasta 100 tablas por semana, y 4) la comparativamente baja demanda externa que, hacia fines de la Colonia, llegó a ser satisfecha con un máximo de 200.000 tablas anuales, equivalente al corte de unos 400 alerces.

En contraposición al escenario colonial, la principal variable que determinó el mayor impacto sobre los alerzales chilotes durante la República fue el notorio aumento de la demanda de madera de alerce, reflejado en la producción y comercio de casi un millón de tablas anuales; escenario que implicó el uso del método de tala indiscriminada, que no diferenciaba el tamaño de los ejemplares que se cortaban. Sin lugar a dudas, la rentabilidad de la actividad maderera generó una enorme presión sobre el recurso, degradándolo rápidamente. No obstante lo anterior, a fines del primer siglo de vida republicana aún se podían reconocer alerzales sobrevivientes, y en buenas condiciones, en los dos sectores menos accesibles de Chiloé, específicamente en las estribaciones occidentales de la cordillera de los Andes y en la cordillera de Piuchén en la Isla Grande.

\section{FUENTES DE CONSULTA}

a) Inéditos

Breve descripción de la provincia de Chiloé, su población, carácter de sus habitantes, producciones y comercio. Biblioteca Nacional, Biblioteca Americana José Toribio Medina, Fondo Manuscritos, Tomo 257, Manuscrito 7464 (Microfilm Ms. M59), fs. 204-234. MS. Santiago de Chile.

Descripción y noticia de las dos naciones Patagónica y Guaigüene, Isla de Chiloé. Biblioteca Nacional, Biblioteca Americana José Toribio Medina, Fondo Manuscritos, Tomo 257, Manuscrito 7454 (Microfilm Ms. M59), fs. 57-79. MS. Santiago de Chile. 
Documentos relativos a Chiloé. Biblioteca Nacional, Biblioteca Americana José Toribio Medina, Fondo Manuscritos, Tomo 259, Manuscrito 7493 (Microfilm Ms. M60), fs. 294-299. MS. Santiago de Chile.

Libro Manual de la Real Caxa de San Carlos de Chiloe. Para la cuenta del año de 1790 del Señor Gobernador Intendente D. ${ }^{n}$ Francisco Garos hasta 8 de Abril y desde el 9 del mismo al de. D. ${ }^{n}$ Juan Tomàs de Vergara Ministro Gral D. ${ }^{n}$ Juan Antonio Arias Interventor. Archivo General de la Nación, Cajas Reales Chiloé, C-15, Legajo 95, Libro 374, 1790. (57 fojas). MS. Lima, Perú.

Libro Mayor de la Real caja de San Carlos de Chiloé. Archivo General de la Nación, Cajas Reales Chiloé, C-15, Legajo 94, Libro 373, 1789 (sin número de fojas). MS. Lima, Perú.

b) Impresos

BERANGER, C. DE. 1893. Relacion Jeográfica de la Isla de Chiloé. Anales de la Universidad de Chile, LXXXIV: 181-243. Santiago de Chile.

DOMEYKO, I. 1850. Exploracion de las lagunas de Llauquigüe i de Pichilaguna - Volcanes de Osorno i de Calbuco Cordillera de Nauelhuapi. Anales de la Universidad de Chile (sin número): 145-147. Santiago de Chile.

FITZROY, R. 1933. Narración de los viajes de levantamiento de los buques de S. M. "Adventure" y "Beagle" en los años 1826 a 1836. Biblioteca del Oficial de Marina, Buenos Aires.

FONCK, F. (ed.). 1896. Viajes de fray Francisco Menéndez a la Cordillera. Imprenta Gillet, Valparaíso, Chile.

LEGUAS, A. 1897. Memoria del ayudante de la comisión, Sr. Aurelio Leguas A. En: Estudios geográficos é hidrográficos sobre Chiloé. R. Maldonado. Establecimiento Poligráfico "Roma", Santiago de Chile, pp. 313-363.

MORALEDA, J. DE. 1888. Breve descripcion de la provincia de Chiloé, su poblacion, carácter de sus habitantes, producciones i comercio. En: Esploraciones Jeográficas e Hidrográficas de José de Moraleda y Montero. Imprenta Nacional, Santiago de Chile; pp. 203-228.

Noticia breve y moderna del Archipiélago de Chiloé, de su terreno, costumbres de los indios, misiones, escrita por un misionero de aquellas islas en el año 1769 y 70. Archivo Romano de la Compañía de Jesus, Chile, V. 5. Roma. En: Hanisch, W. 1982. La Isla de Chiloé, Capitana de Rutas Australes. Academia Superior de Ciencias Pedagógicas de Santiago/Alfabeta Impresores, Santiago de Chile; pp. 220-263.
O'HIGGINS, T. 1942. Diario de viaje del capitán D. Tomás O'Higgins, de orden del virrey de Lima, el marqués de Osorno. 1796-1797. Revista Chilena de Historia y Geografía, 101: 42-97. Santiago de Chile.

RIBERA, L. De. 1897. Discurso que hace el alferez don Lázaro de Ribera, injeniero delineador, sobre la Provincia de Chiloé por órden del Supremo Gobierno de Lima, desde esta misma ciudad en agosto de 1782. En: Cinco relaciones Jeográficas e Hidrográficas que interesan a Chile. N. Anrique (ed.). Imprenta Elseviriana, Santiago de Chile; pp. 1-67.

VIDAL GORMAZ, F. 1871. Esploracion de la costa de Llanquihue i archipiélago de Chiloé practicada por órden del supremo Gobierno por el capitan graduado de corbeta don Francisco Vidal Gormaz. Anales de la Universidad de Chile, XXXIX: 5-80. Santiago de Chile.

WILLIAMS, J. 1859. Lijera reseña del rio maullin de Chiloé, acompañada de una sucinta direccion para la navegacion de la entrada de dicho rio; por el capitan de corbeta don Juan Williams. Anales de la Universidad de Chile, XVI: 392-401. Santiago de Chile.

\section{BIBLIOGRAFÍA}

ABARZÚA, A., C. VILLAGRÁN y P. MORENO 2004. Deglacial and postglacial climate history in east-central Isla Grande de Chiloé, Southern Chile ( $\left.43^{\circ} \mathrm{S}\right)$. Quaternary Research, 62: 49-59.

ARMESTO, J., C. VILLAGRÁN y C. DONOSO 1994. Desde la era glacial a la Industrial: la historia del bosque templado chileno. Ambiente y Desarrollo, 19: 66-72.

BENOIT, I. (ed.) 1989. Red List of Chilean Terrestrial Flora (Part One). CONAF, Santiago.

BOLÓS, M. DE. 1992. La evolución o arqueología del paisaje. En: Manual de ciencia del paisaje teoría, métodos y aplicaciones. M. de Bolós (ed.). Masson S.A., Barcelona; pp. 191-203.

CAMUS, P. 2002. Bosques y tierras despejadas en el período de la conquista de Chile. En: Estudios Coloniales II. J. Retamal (ed.). RIL Editores, Santiago de Chile; pp. 159-180.

CARABIAS, D., N. LIRA y L. ADÁN 2010. Reflexiones en torno al uso de embarcaciones monóxilas en ambientes boscosos lacustres precordilleranos andinos, zona centro-sur de Chile. Magallania, 38: 87-108. Punta Arenas, Chile.

CÁRDENAS, R., D. MONTIEL y C. HALL 1991. Los Chonos y los Veliches de Chiloé. Ediciones Olimpho, Santiago de Chile.

CLAUDE, J. 1931. La vivienda araucana. Anales de la Universidad de Chile, $3^{\text {a }}$ Serie, I: 29-48. Santiago de Chile. 
CONTRERAS, J., E. FLORES, I. HERRERA, L. MAZZEI, A. RIVERA y R. ROMERO 1971. La población y la economía de Chiloé durante la colonia (1567-1826). Universidad de Concepción, Concepción, Chile.

COROMINAS, J. 1976. Diccionario crítico etimológico de la Lengua Castellana. Editorial Gredos, Madrid.

CUNILL, P. 1971. Chile meridional criollo: su geografía humana en 1700. Cuadernos Geográficos del Sur, Número único: 21-75. Concepción, Chile.

DONOSO, C. 1993. Bosques templados de Chile y Argentina. Variación, estructura y dinámica. Editorial Universitaria, Santiago de Chile.

DONOSO, C., V. SANDOVAL y R. GREZ 1990. Silvicultura de los bosques de Fitzroya cupressoides. ¿Ficción o realidad? Bosque 11: 57-67. Valdivia, Chile.

ERIZE, E. 1960. Diccionario comentado Mapuche-Español. Cuadernos del Sur, Buenos Aires.

FINSTERBUSCH, C. A. 1934. Las dalcas de Chiloé y los chilotes. Revista Chilena de Historia y Geografía 82: 412-433. Santiago de Chile.

FRAVER, S., M. GONZÁLEZ, F. SILLA, A. LARA y M. GARDNER 1999. Composition and structure of remnant Fitzroya cupressoides forest of Southern Chile's Central Depression. Journal of the Torrey Botanical Society, 126: 49-57. Lawrence, US.

GAY, C. 1849. Historia Física y Política de Chile. Botánica. Imprenta de $\mathrm{E}$. Thunot y $\mathrm{C}^{\mathrm{a}}$, Paris.

GERDING, V. y Y. RIVAS 2006. Desarrollo de plantaciones experimentales jóvenes de Fitzroya cupressoides establecidas en el arboreto de la Universidad Austral de Chile, Valdivia. Bosque 27: 155-162. Valdivia, Chile.

GONZÁLEZ DE AGÜEROS, P. 1791. Descripción historial de la provincia y archipielago de Chilóe, en el Reyno de Chile, y obispado de la Concepcion. En la Imprenta de Don Benito Cano, España.

GUARDA, G. 1990. Flandes indiano. Las fortificaciones del reino de Chile (1541-1826). Ediciones de la Universidad Católica, Santiago de Chile.

HANISCH, W. 1882. La Isla de Chiloé, Capitana de Rutas Australes. Academia Superior de Ciencias Pedagógicas de Santiago/Alfabeta Impresores, Santiago de Chile.

KITZBERGER, T., A. PEREZ, G. IGLESIAS, A. PREMOLI y T. VEBLEN 2000. Distribución y estado de conservación del Alerce (Fitzroya cupressoides (Mol.) Johnst.) en Argentina. Bosque, 21: 79-89. Valdivia.

LARA, A. y R. VILLALBA. 1993. A 3620-year temperature record from Fitzroya cupressoides tree rings in southern South America. Science 260: 1104-1106. Washington, DC.
LATCHAM, R. 1936. Prehistoria chilena. Oficina del Libro, Santiago de Chile.

MALDONADO, R. 1897. Estudios geográficos é hidrográficos sobre Chiloé. Establecimiento Poligráfico Roma, Santiago de Chile.

MEDINA, J.T. 1906. Diccionario Biográfico Colonial de Chile. Imprenta Elzeviriana, Santiago de Chile.

MEDINA, A. 1984. Embarcaciones chilenas precolombinas. La Dalca de Chiloé. Revista Chilena de Antropología 4: 121-138. Santiago de Chile.

MOLINA, R., M. CORREA, C. SMITH-RAMIREZ y A. GAINZA 2006. Alerceros huilliches de la cordillera de la costa de Osorno. Andros Impresores, Santiago de Chile.

MORENO, P. 2004. Millenial-scale climate variability in northwest Patagonia over the last 15000 yr. Journal of Quaternary Science 19: 35-47. W. Sussex, UK.

OLGUÍN, C. 1971. Instituciones políticas y administrativas de Chiloé en el siglo XVIII. Editorial Jurídica, Santiago de Chile.

OVALLE, A. De. 1646. Historica Relacion del Reyno de Chile. Por Francisco Caballo, Roma.

OYARZÚN, A. 1934. Cultura aborigen de Chiloé. Revista Chilena de Historia y Geografía 83: 235-254, Santiago de Chile.

PAGÉS, A. DE. (sin fecha). Gran diccionario de la Lengua Castellana (de autoridades) con ejemplos de buenos escritores antiguos y modernos. Imprenta de Ángel Ortega, Barcelona.

PREMOLI, A., C. SOUTO, A. LARA y C. DONOSO 2004. Variación en Fitzroya cupressoides (Moll) Johnston (Alerce o Lahuán). En: Variación intraespecífica en las especies arbóreas de los bosques templados de Chile y Argentina. C. Donoso, A. Premoli, L. Gallo y R. Ipinza (eds.). Editorial Universitaria, Santiago de Chile; pp. 277-301.

R.A.E. 1933. Diccionario Histórico de la Lengua Española. Imprenta de Librería y Casa Editorial Hernandon, Madrid.

R.A.E. 1992. Diccionario de la lengua española. EspasaCalpe, Madrid.

RAMÍREZ, F. 1996. Ecohistoria y destrucción en Chiloé Continental: El Valle del Vodudahue 1700-1996. En: Bases históricas del desarrollo regional de Chile. Actas de la VII Jornada Nacional de Historia Regional de Chile, 225-257, Universidad de Chile, Santiago de Chile.

REICHE, K. 1934. Geografía Botánica de Chile. Imprenta Universitaria, Santiago de Chile

REYES, R. y H. LOBOS 2000. Estado de conservación del tipo forestal alerce (Fitzroya cupressoides (Mol.) Johnston): amenazas y oportunidades. Bosque Nativo, 27:14-15. Valdivia, Chile. 
RODRÍGUEZ, R., O. MATTHEI y M. QUEZADA 1983. Flora Arbórea de Chile. Editorial de la Universidad de Concepción, Concepción, Chile.

ROSALES, D. DE. 1877. Historia general del Reyno de Chile. Flandes Indiano. Imprenta del Mercurio, Valparaíso, Chile.

STEFFEN, H. 1913. Documentos relativos a una espedicion colonial a las cordilleras australes de Chile. Imprenta, Litografía i Encuadernacion Barcelona, Santiago de Chile.

TORREJÓN, F., M. CISTERNAS y A. ARANEDA 2004.

Efectos ambientales de la colonización española desde el río Maullín al archipiélago de Chiloé, sur de Chile. Revista Chilena de Historia Natural, 77:661-677. Santiago de Chile.

TORNERO, R. 1872. Chile Ilustrado. Guía descriptivo del territorio de Chile, de las capitales de provincia, i de los puertos principales. Librerias i Ajencias del Mercurio, Valparaíso, Chile.
URBINA, M. 2009. La frontera de arriba en Chile colonial. Ediciones Universitarias, Valparaíso, Chile.

URBINA, R. 1983. La periferia meridional indiana Chiloé en el siglo XVIII. Ediciones Universitarias, Valparaíso, Chile.

VILLAGRÁN, C. 1991. Historia de los bosques templados del sur de Chile durante el Tardiglacial y Postglacial. Revista Chilena de Historia Natural, 64: 447-460. Santiago, Chile.

WEBER, A. 1903. Chiloé su estado actual, su colonización, su porvenir. Imprenta Mejía, Santiago de Chile.

WOLODARSKY-FRANKE, A. y A. LARA 2003. La dendrocronología como herramienta en la conservación de especies arbóreas en peligro en Chile, Gestión Ambiental, 9:15-23. Valdivia, Chile.

ZAPATER, H. 1973. Los aborígenes chilenos a través de cronistas y viajeros. Editorial Andrés Bello, Santiago de Chile. 
F. TORREJÓN, M. CISTERNAS, I. ALVIAL Y L. TORRES 